\title{
Identification of phytocompounds from Houttuynia cordata Thunb. as potential inhibitors for SARS-CoV-2 replication proteins through GC-MS/LC-MS characterization, molecular docking and molecular dynamics simulation
}

\author{
Sanjib Kumar Das ${ }^{1} \cdot$ Saurov Mahanta ${ }^{2} \cdot$ Bhaben Tanti $^{3} \cdot$ Hui Tag $^{4} \cdot$ Pallabi Kalita Hui ${ }^{1}$
}

Received: 28 January 2021 / Accepted: 22 April 2021 / Published online: 7 May 2021

(c) The Author(s), under exclusive licence to Springer Nature Switzerland AG 2021

\begin{abstract}
The COVID-19 pandemic caused by Severe Acute Respiratory Syndrome Coronavirus 2 (SARS-CoV-2) is a massive viral disease outbreak of international concerns. The present study is mainly intended to identify the bioactive phytocompounds from traditional antiviral herb Houttuynia cordata Thunb. as potential inhibitors for three main replication proteins of SARSCoV-2, namely Main protease (Mpro), Papain-Like protease (PLpro) and ADP ribose phosphatase (ADRP) which control the replication process. A total of 177 phytocompounds were characterized from H. cordata using GC-MS/LC-MS and they were docked against three SARS-CoV-2 proteins (receptors), namely Mpro, PLpro and ADRP using Epic, LigPrep and Glide module of Schrödinger suite 2020-3. During docking studies, phytocompounds (ligand) 6-Hydroxyondansetron (A104) have demonstrated strong binding affinity toward receptors Mpro (PDB ID 6LU7) and PLpro (PDB ID 7JRN) with G-score of -7.274 and -5.672 , respectively, while Quercitrin (A166) also showed strong binding affinity toward ADRP (PDB ID 6W02) with G-score -6.788. Molecular Dynamics Simulation (MDS) performed using Desmond module of Schrödinger suite 2020-3 has demonstrated better stability in the ligand-receptor complexes A104-6LU7 and A166-6W02 within 100 ns than the A104-7JRN complex. The ADME-Tox study performed using SwissADMEserver for pharmacokinetics of the selected phytocompounds 6-Hydroxyondansetron (A104) and Quercitrin (A166) demonstrated that 6-Hydroxyondansetron passes all the required drug discovery rules which can potentially inhibit Mpro and PLpro of SARS-CoV-2 without causing toxicity while Quercitrin demonstrated less drug-like properties but also demonstrated as potential inhibitor for ADRP. Present findings confer opportunities for 6-Hydroxyondansetron and Quercitrin to be developed as new therapeutic drug against COVID-19.
\end{abstract}

Sanjib Kumar Das and Saurov Mahanta have contributed equally to this work.

Hui Tag

hui.tag@rgu.ac.in

$\triangle$ Pallabi Kalita Hui

pallabi2008rgu@gmail.com; pallabikalita@nitap.ac.in

1 Department of Biotechnology, National Institute

of Technology, Arunachal Pradesh, Yupia,

Arunachal Pradesh 791112, India

2 National Institute of Electronics and Information Technology, Guwahati, Assam 781008, India

3 Department of Botany, Gauhati University, Guwahati, Assam 781014, India

4 Pharmacognosy and Phytochemistry Research Laboratory, Department of Botany, Rajiv Gandhi University, Rono Hills, Doimukh, Arunachal Pradesh 791112, India 


\section{Graphic abstract}

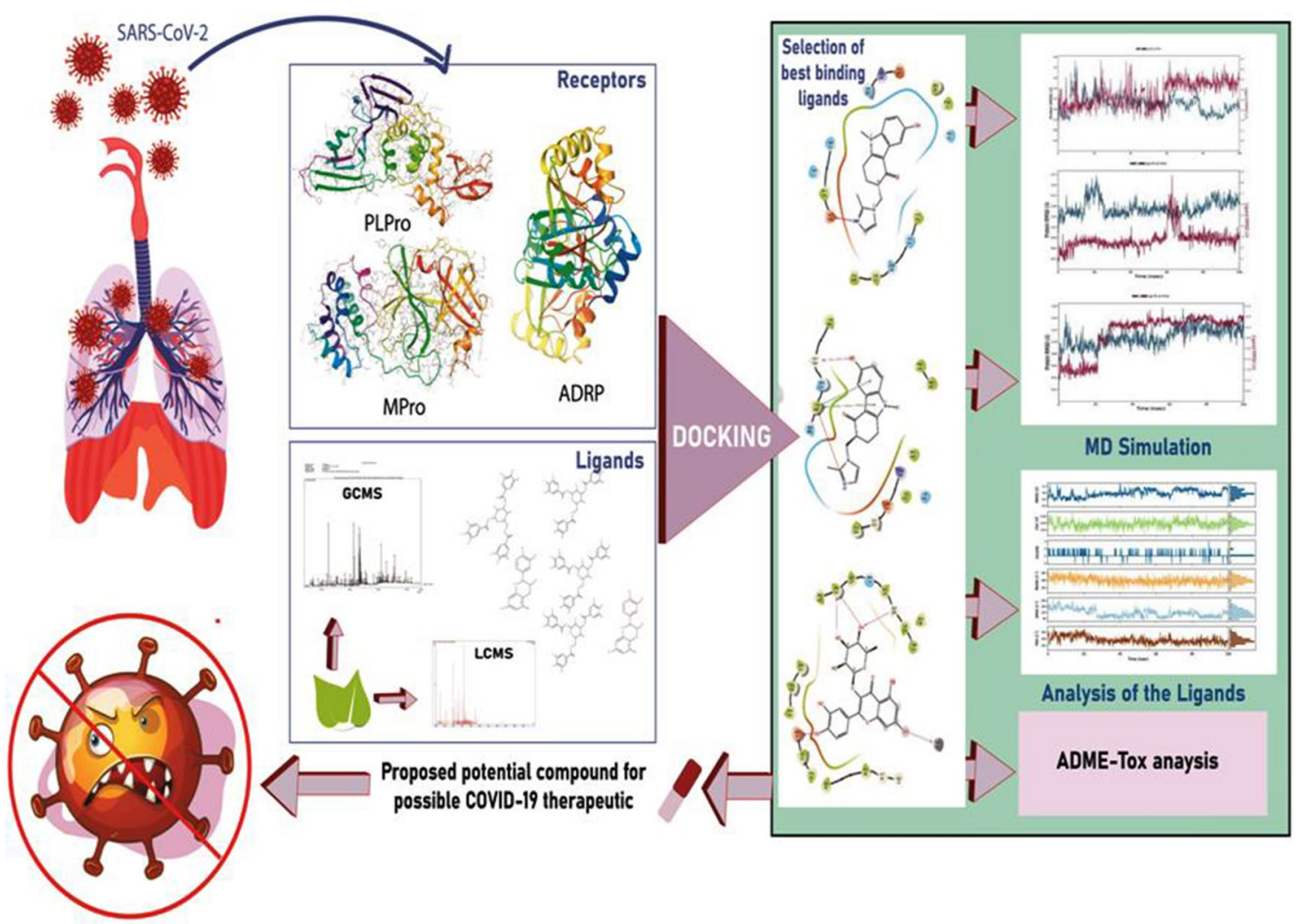

Keywords SARS-CoV-2 proteins $\cdot$ Houttuynia cordata $\cdot$ Inhibitor phytocompounds $\cdot$ GC-MS/LC-MS $\cdot$ Molecular docking $\cdot$ Molecular dynamics

\section{Abbreviations}

ADME-Tox Adsorption, digestion, metabolism, excretion and toxicity

$\begin{array}{ll}\text { ADRP } & \text { ADP ribose phosphatase } \\ \text { COVID-19 } & \text { Coronavirus disease 2019 } \\ \text { MDS } & \text { Molecular dynamics simulation } \\ \text { Mpro } & \text { Main protease } \\ \text { PDB ID } & \text { Protein Data Bank Identity } \\ \text { PLpro } & \text { Papain-like protease } \\ \text { RMSD } & \text { Root-mean-square deviation } \\ \text { RMSF } & \text { Root-mean-square fluctuation }\end{array}$

SARS-CoV-2 Severe acute respiratory syndrome coronavirus 2

\section{Introduction}

Sudden outbreak of COVID-19 has become life threatening for millions of human population across the globe. World Health Organization (WHO) declared COVID-19 as the 6th public health emergency of international concern on 30th
January 2020. WHO reported 760.2 million active cases of COVID-19 followed by 16.6 millions of confirmed deaths globally till the month of December, 2020 [1]. The COVID19 is fundamentally caused by the infection of severe acute respiratory syndrome coronavirus 2 (SARS-CoV-2) in the human host and transmits to another human being through physical contact or droplets. Although antiviral drug and vaccine development are being undertaken for the prevention of the disease, presently, there are no effective therapeutic drug molecules available to date against COVID-19. SARS-CoV-2 is an enveloped virus that belongs to family of Coronaviridae containing single positive-stranded RNA and replicate inside the cytoplasm of human cell [2, 3]. SARS-CoV-2 genome encodes several proteins that are involved in the replication of viral genome. Inhibition of the expression of these receptor proteins may lead to the possibilities of anti-SARS-CoV-2 drug development for effective treatment of COVID-19. Three proteins of SARS-CoV-2, namely Main protease (Mpro), Papain-Like protease (PLpro) and ADP ribose phosphatase (ADRP), are reported to be mainly responsible for SARS-CoV-2 replication process 
[4]. The Main protease (Mpro) is present in SARS-CoV-2 and other coronaviruses (CoVs) which cleave two replicase polyprotein responsible for viral replication and maturation [5]. The papain-like protease (PLpro) is another proteolytic enzyme which is essential for processing of SARS-CoV-2 polyproteins to generate a functional replicase complex and initiate viral spread. PLpro is also involved in cleaving protein during post-translational modifications on host proteins as an eluding mechanism against host antiviral immune responses. PLpro cleaves ubiquitin and ISG15 which are known regulators of host innate immune pathways [6]. On the other hand, ADP ribose phosphatase (ADRP) is known enzymes of SARS-CoV-2 replication that convert ADP-ribose 1"-monophosphate (Appr-1"-p) to ADP-ribose (Appr), which regulate replication of the virus [7]. Therefore, inhibition of Mpro, PLpro and ADRP activities through bioactive phytochemical drug molecules would prevent replication mechanism of SARS-CoV-2.

In silico method employed for the screening of potential drug molecules is proven rapid and cost effective while compared with the trial and error methods using experimental studies. Molecular docking is an in silico approach with ability to screen and identify potential drug molecules from large and massive bioactive compound libraries. Currently, several molecular docking studies were carried out against SARS-CoV-2 receptors with some selected bioactive compounds (Table 1 ) and have been able to identify few potential compounds drug molecules effective against targeted receptors of COVID-19 [7, 9-14]. However, most of these docking studies relied on structure-based drug design (SBDD), as well as similarity searching and quantitative structure-activity relationship (QSAR) modeling [8]. Some recent cases of molecular docking studies of different molecular targets for SARS-CoV-2 are presented in Table 1.

The traditional healer of different ethnic communities used medicinal plants for treatment and prevention of various diseases including viral infections. Isolation of these bioactive phytocompounds from traditional medicinal plants may lead to the development of antiviral drug for effective treatment of COVID-19 [15]. Houttuynia cordata Thunb. is a herb belonging to the family Saururaceae, distributed in China, India, Bangladesh, Cambodia, East Himalaya, Hainan, Japan, Korea, Myanmar, Nepal, Taiwan, Thailand, Tibet (China), Vietnam, West Himalaya [16]. The whole plant is used in folk medicine for the treatment of cough, pneumonia, bronchitis, dysentery, dropsy, leukorrhea, uteritis, eczema, herpes simplex, acne, chronic sinusitis, stomach ulcer, infection, control wrinkle, chapped skin, septic, febrifuge, heatstroke, malaria, lung disorder, tonsillitis, skin ulcer, diarrhea, dysentery arthritis, appendicitis, and snake bite in Japan, Korea, Indonesia and Myanmar [17-19]. In Indian sub-continent, $H$. cordata is mainly used for the treatment and prevention of pneumonia, stomach disorder, sinusitis and heart disorders by the indigenous tribes of North East

Table 1 Molecular docking studies of different molecular targets for SARS-CoV-2

\begin{tabular}{|c|c|c|c|}
\hline Targeted receptors of SARS-CoV-2 & Experiment & $\begin{array}{l}\text { Identified potential antiviral drug candidates for } \\
\text { SARS-CoV-2 }\end{array}$ & References \\
\hline Mpro & Molecular docking & $\begin{array}{l}\text { Hesperidin, rutin, diosmin, apiin, diacetylcurcumin, } \\
\text { (E)-1-(2-Hydroxy-4-methoxyphenyl)-3-[3-[(E)-3- } \\
\text { (2-hydroxy-4- methoxyphenyl)-3-oxoprop-1-enyl] } \\
\text { phenyl] prop-2-en-1-one, and beta, beta'-(4-Meth- } \\
\text { oxy-1,3- phenylene) bis(2'-hydroxy-4',6'- } \\
\text { dimethoxyacrylophenone }\end{array}$ & [9] \\
\hline Mpro & $\begin{array}{l}\text { Molecular docking } \\
\text { and drug ability } \\
\text { studies }\end{array}$ & $\begin{array}{l}\text { Glycyrrhizin, bicylogermecrene, tryptanthrine, } \\
\beta \text {-sitosterol, indirubin, indican, indigo, hes- } \\
\text { peretin, crysophanic acid, rhein, berberine and } \\
\beta \text {-caryophyllene }\end{array}$ & {$[10]$} \\
\hline $\begin{array}{l}\text { Spike (S) glycoprotein, Mpro and RNA-dependent } \\
\text { RNA polymerase (RdRp) }\end{array}$ & Molecular docking & Silybin and withaferin A & [11] \\
\hline Spike glycoprotein and ACE2 receptor & Molecular docking & $\begin{array}{l}\text { Curcumin, nimbin, withaferin A, piperine, mangif- } \\
\text { erin, thebaine, berberine, rographolide resveratrol, } \\
\text { quercetin, luteolin, naringenin, zingiberene, and } \\
\text { gallic acid }\end{array}$ & {$[12]$} \\
\hline $\begin{array}{l}\text { Mpro, endoribonucleoase (Nsp15/NendoU), ADP- } \\
\text { ribose-1"-phosphatase (ADRP), RNA-dependent } \\
\text { RNA polymerase (RdRp), }\end{array}$ & Molecular docking & $\begin{array}{l}\text { Sesquiterpene hydrocarbon }(E) \text { - } \beta \text {-farnesene, }(E, E) \text { - } \\
\alpha \text {-farnesene, }(E) \text { - } \beta \text {-farnesene, }(E, E) \text { - farnesol }(E \text {, } \\
E) \text {-Farnesol }\end{array}$ & [7] \\
\hline 3CL-PRO, PL-PRO & Molecular Docking & saikosaponin D and amentoflavone & {$[13]$} \\
\hline ACE2 & $\begin{array}{l}\text { Molecular docking } \\
\text { and molecular } \\
\text { dynamics studies }\end{array}$ & Hesperidin & {$[14]$} \\
\hline
\end{tabular}


India [20-22]. The major bioactive phytocompounds including flavonoid, alkaloid, as well as essential oil, have been reported from various parts of $H$. cordata which possesses antimicrobial, hepatoprotective, anti-inflammatory, antioxidative, anticancer, anti-diabetic, anti-obesity and antiviral properties [17]. Houttuynia cordata was one of the most important ingredient of the herbal formulation used for the treatment of Severe Acute Respiratory Syndrome (SARS) outbreak of Southern China in 2003 [16]. Several scientific studies also reveal that the extract of $H$. cordata has the potential to inhibit replication of the various viral strains including SARS coronavirus (SARS-CoV), Chikungunya, Herpes simplex viruses, dengue virus serotype 2 (DEN-2), Influenza neuraminidase, pseudorabies herpes virus (PrV), Human noroviruses (HuNoVs), murine coronavirus and dengue virus infection and also possess innate immune modulation activities [16, 18, 23-29].

Therefore, considering the therapeutic importance of $H$. cordata with strong ethnopharmacological use background, the present study is mainly intended to characterize the bioactive phytocompounds by using gas chromatography-mass spectrometry (GC-MS) and liquid chromatography-mass spectrometry (LC-MS) studies, and to perform molecular docking studies of bioactive phytocompounds against the three main proteins (target receptors) of SARS-CoV-2, namely Mpro, PLpro and ADRP, responsible for replication process of the virus, and to identify the bioactive phytocompounds (ligands) potential to inhibit SARS-CoV-2 replication proteins by determining the binding affinities of the ligands against selected receptors. We performed molecular docking study between the active phytochemicals of $\mathrm{H}$. cordata using Epic, LigPrep and Glide module of Schrödinger suite 2020-3 followed by Molecular Dynamics simulation by Desmond module of Schrödinger suite 2020-3. We also performed Adsorption, Digestion, Metabolism, Excretion and Toxicity (ADME-Tox) study of the shortlisted phytocompounds using SwissADMEserver to evaluate pharmacokinetics, drug-likeness and medicinal chemistry friendliness of the selected bioactive phytocompounds.

\section{Materials and methods}

\section{Collection of sample}

The herb H. cordata was collected on 13 November 2019 from Ziro valley of Lower Subansiri District of Arunachal Pradesh, India $\left(26^{\circ} 55^{\prime}-28^{\circ} 21^{\prime} \mathrm{N}\right.$ and $\left.92^{\circ} 40^{\prime}-94^{\circ} 21^{\prime} \mathrm{E}\right)$. The plant materials were identified and authenticated at ASSAM Herbarium, Botanical Survey of India, Eastern Regional Center, Shillong, Meghalaya, India. The accepted names and global distribution ranges were verified in http:// www.plantsoftheworldonline.org (POWO) hosted by Royal
Botanic Garden, Kew, UK. The voucher specimen No. SD/ HAU-0110 dated 13.11.2019 was deposited in the Herbarium of Arunachal University (HAU), Department of Botany, Rajiv Gandhi University, Rono Hills, Doimukh, Arunachal Pradesh, India for future references. The fresh herb harvested was washed in running tap water to remove microflora, dirt and soil particles and then shade dried at normal room temperature $\left(20.0-27.0^{\circ} \mathrm{C}\right)$ with proper ventilation. The minimum moisture content of the dried samples was maintained at 15\% using Material Moisture Meters (Model Testo 606-1, Germany). The powdered samples were passed through 40-mesh sieve and stored for further use.

\section{Characterization of bioactive phytocompounds}

\section{Preparation of crude extract}

The crude extract was prepared by cold maceration of powder materials with methanol (solvent ratio 1:5). $50 \mathrm{~g}$ of powder sample was soaked in $250 \mathrm{ml}$ of methanol and placed on magnetic stirrer for $48 \mathrm{~h}$ [30]. After $48 \mathrm{~h}$, filtrate was collected through Whatman No. 1 filter paper and concentrated the sample in a rotary evaporator (IKA Model No. GS90A24), set at temperature $70{ }^{\circ} \mathrm{C}$, run at $40 \mathrm{rpm}$. The concentrated samples were then further subjected to dry in water bath (I THERM Model No. BTI 57) and then in hot air oven (I THERM Model No. BTI 29) at $40{ }^{\circ} \mathrm{C}$, until the constant weight of extracts was observed. The crude extract obtained was further used for characterization of bioactive phytochemicals using GC-MS and LC-MS.

\section{GC-MS analysis}

The GC-MS characterization of crude extract of $H$. cordata was performed by injecting $2 \mu \mathrm{l}$ of sample in a GC-MS-2010 Shimadzu instrument operating in EI mode at $70 \mathrm{eV}$ with Restek-5MS column $(30 \times 0.25 \mathrm{~mm}$ film thickness $0.25 \mu \mathrm{m})$. The oven temperature was programmed as follows: kept at $60{ }^{\circ} \mathrm{C}$ for $2 \mathrm{~min}$, then increased to $210{ }^{\circ} \mathrm{C}$, at $3{ }^{\circ} \mathrm{C} \mathrm{min}{ }^{-1}$ and from $210-280^{\circ} \mathrm{C}$ at the rate of $8{ }^{\circ} \mathrm{C} / \mathrm{min}$ and held for $8 \mathrm{~min}$ at $280^{\circ} \mathrm{C}$. The injector temperature was $260^{\circ} \mathrm{C}$ with normal injection mode. The flow rate of carrier helium gas was $1.21 \mathrm{ml} / \mathrm{min}$. For the plant samples, the temperature program was set according to Jiang et al. [31]. Mass spectra were acquired using full scan monitoring mode with a mass scan range of $40-650 \mathrm{~m} / \mathrm{z}$. The chromatogram and mass spectra were evaluated using the Xcalibur ${ }^{\mathrm{TM}}$ software embedded in the GC-MS/LC-MS system. Interpretation on mass spectrum GC-MS was conducted using the database of National Institute Standard and Technology (NIST), Wiley having more than 62,000 patterns and Dr. Duke's phytochemical ethnobotanical databases (Duke 2018; phytochem. nal.usda.gov). The spectrum of the unknown component 
was compared with the spectrum of the known components stored in the NIST library. The name, molecular weight and structure of the compounds of the test materials were ascertained.

\section{LC-MS analysis}

The LC-MS characterization of the $H$. cordata was performed by injecting $10 \mu \mathrm{l}$ of sample in a LC-MS Thermo Scientific Plus with Dionex Ultimate 3000 HPLC with column Hypersil Gold (C18) Diameter $150 \times 2.1 \mathrm{~mm}$, Particle Size $1.9 \mu$ at room temperature. The mobile phases used were $\mathrm{A}$ (acetonitrile) and $\mathrm{B}(0.2 \%$ aqueous acetic acid, $\mathrm{v} / \mathrm{v})$. The run time was set for 20 min followed by flow rate of $0.6 \mathrm{~mL} / \mathrm{min}$. DAD detector was set at $280 \mathrm{~nm}$ for acquiring chromatograms. The mass spectrometer used was a Triple quadruple Mass Spectrometer (Thermo Scientific) equipped with ion sources ESI with Mass range for full scans $\mathrm{m} / \mathrm{z}$ 50-6000. All raw data acquired were processed by METLIN database [32].

\section{Molecular docking}

\section{Preparation of receptor proteins}

The crystal structure of SARS-CoV-2 main protease in complex with an inhibitor N3 having PDB ID 6LU7 [33] (resolution $2.16 \AA$ ), wild type SARS-CoV-2 papain-like protease (PLPro) with inhibitor GRL0617 having PDB ID 7JRN (resolution 2.48 $\AA$ ) and ADP ribose phosphatase of NSP3 from SARS-CoV-2 in the complex with ADP ribose having PDB ID 6W02 (resolution 1.5 ^) were downloaded from RCSB Protein Data Bank [34] and same were processed through protein preparation wizard of Epic module [35] of Schrödinger suite 2020-3. The proteins were prepared by removing similar binding sites, unnecessary water molecules and also refining bond orders. Missing chain atoms were added by using the prime module of Schrödinger suite 2020-3. Energy minimization of the proteins was performed using optimized potentials for liquid simulations-3 (OPLS3e) molecular force field with root-mean-square difference (RMSD) of crystallographic heavy atoms kept at $0.3 \AA$. The ligand binding information of N3, GRL0617 and ligand binding pocket of ADP ribose were used for prediction of the active site of the proteins.

\section{Preparation of ligand library}

The ligand library from the GC-MS and LC-MS analysis of $H$. cordata, having traditional medicinal linkage with antiviral treatment, was processed through the LigPrep module of Schrödinger suite 2020-3. During preparation of the ligands for docking, Lipinski Drug Discovery rule [36] was kept as filtering criteria to screen out unfavorable molecules from the dataset. 2D structures were converted to 3D structures, and optimized for their geometry, desalted and their chirality was corrected. The ionization and tautomeric states were generated between $\mathrm{pH} 6.8$ and 7.2 by using Epik module of Schrödinger suite 2020-3. The ligands were minimized using OPLSe-3 force field in Schrödinger suite 2020-3 until a RMSD of $2.0 \AA$ was achieved and the optimized ligands were used for docking analysis.

\section{Protein-Ligand docking using glide}

The filtered phytocompounds were prepared by LigPrep module of Schrödinger suite before proceeding for docking, and the docking was performed against each of the three selected receptor proteins, Mpro (PDB ID 6LU7), PLpro (PDB ID 7JRN) and ADRP (PDB ID 6W02) using Glide module of Schrödinger suite 2020-3. During the docking process, the receptor grid maps were prepared from the active site information available from the previously bound ligands with the receptor in crystal structure available from RCSB PDB. The binding modes with best docking score and best Glide gscores (G-Score) were selected. These scores perceive positive lipophilic, hydrogen bonding and metal-ligand associations and punish steric conflicts. The G-scoring capacity is mainly dependent on docking parameters like lipophilic perseverance in which the ligands are covered in the lipophilic pocket. The electrostatic forces and hydrogen bonding with ligands are other parameters to increase the binding affinity.

\section{Molecular dynamics simulation}

For Molecular Dynamics (MD) Simulation, the Desmond module through Maestro of Schrödinger suite 2020-3 was used in the Linux platform supported by 6 GB NVIDIA GeForce GTX graphics card. To study the stability of the docked complex with the ligand, an MD Simulation study of 100 nano second (ns) was performed [37]. The complex in the explicit solvent system with the OPLS3e force field was studied using the Desmond module of Schrödinger suite 2020-3. The molecular system was solvated with crystallographic water (TIP3P) molecules under orthorhombic periodic boundary conditions for a $10 \AA$ buffer region. The overlapping water molecules are deleted, and the system was neutralized by adding $\mathrm{Na}+$ as counter ions. An ensemble (NPT) of Nose-Hoover thermostat [38] and barostat was applied to maintain the constant temperature $(300 \mathrm{~K})$ and pressure (1 bar) of the systems, respectively. A hybrid energy minimization algorithm with 1000 steps of steepest descent followed by conjugate gradient algorithms was utilized. 


\section{Root-mean-square deviation (RMSD)}

The structure and dynamic properties of the protein-ligand complexes were analyzed as the backbone RMSDs during the simulation period of $100 \mathrm{~ns}$. The RMSD was measured as the average distance between the backbone atoms of the protein-ligand structures and it was derived from the following equation:

$\mathrm{RMSD}=\sqrt{\frac{1}{N} \sum_{i=0}^{N} \delta_{i}^{2}}$

where $N$ represents the total number of atoms considered in the calculation and $\delta$ represents the distance between the $N$ pairs of equivalent atoms.

\section{The root-mean-square fluctuations (RMSF)}

The root-mean-square fluctuations (RMSF) were assessed and plotted to equate the flexibility of each residue in the ligand-protein complexes. The RMSF of the protein-ligand complex denoted the minimized fluctuation for all the complexes.

\section{ADME-Tox study}

Adsorption, Digestion, Metabolism, Excretion and Toxicity (ADME-Tox) study of the shortlisted compounds was performed using Swiss ADMEserver (http://www.swiss adme.ch) [39]. [SwissADME: a free web tool to evaluate pharmacokinetics, drug-likeness and medicinal chemistry friendliness of small molecules. Sci. Rep. (2017) 7:42717.].

\section{Result}

\section{Characterization of bioactive phytocompounds}

\section{GC-MS analysis}

GC-MS analysis of $H$. cordata has identified and quantified 80 phytocompounds and the result is summarized in Table 2. The chromatograms of GC-MS result are given as Fig. 1.

\section{LC-MS analysis}

The non-volatile compounds were identified by LC-MS. Ninety-seven phytocompounds were identified by LC-MS. The result of LC-MS is summarized in Table 3 and chromatogram is presented as Fig. 2.

\section{Molecular docking}

The molecular docking of ligands (bioactive phytocompounds from $H$. cordata) was carried out against three different receptors of SARS-CoV-2, namely Mpro (PDB ID 6LU7), PLpro (PDB ID 7JRN) and ADRP (PDB ID 6W02), respectively, by using an advanced molecular docking program, Glide of Schrödinger suite 2020-3 to determine the binding affinities of the ligands against selected receptors. The binding affinities of the ligands toward receptors were determined based on Docking Score and Glide gscore. Lower docking score and Glide gscore indicate better affinity. The results of the molecular docking study revealed that the bioactive phytocompound coded with A107 from $H$. cordata showed highest binding affinity toward Mpro (6LU7) with G-Score - 7.929 (Table 4). The bioactive phytocompounds A104, A120, A99 and A127 from H. cordata also showed significant binding affinities against Mpro (6LU7) with G-score $-7.274,-7.024,-6.883$ and-6.793, respectively (Table 4). Similarly, bioactive phytocompounds A105 showed highest binding affinity against PLpro (7JRN) with G-Score - 5.843, and bioactive phytocompounds A140, A104, A100 and A106 showed potential binding affinities against PLpro (7JRN) with G-score -5.779 , - 5.672, -5.602 and -5.227 , respectively (Table 4). ADRP (6W02) is another important protein that is required for SARSCoV-2 replication against which the bioactive phytocompounds A166 showed highest binding affinity with G-Score (-6.788). The phytocompounds A165, A163, A167, A164 showed binding affinity against ADRP (6W02) with G - Score $-6.099,-5.703,-5.703$ and -5.206 , respectively (Table 4). From the present study, it is suggested that the bioactive phytocompound A104 is capable of binding both Mpro (6LU7) and PLpro (7JRN) which has demonstrated multi-targets ability and have been identified as a viable drug molecule potential to inhibit replication proteins Mpro (6LU7) and PLpro (7JRN) of SARS-CoV-2.

Although A107 and A105/A140 have the highest predicted affinity toward Mpro (6LU7) and PLPro (7JRN), the phytocompound A104 was selected for further analysis because of its ability to bind both the receptors. Binding affinities with formation of $\mathrm{H}$-bonds and other non-bonding interactions of the complexes are presented in Fig. 3a, b. On the other hand, the best binding ligand A166 was selected for further analysis against the target protein ADRP and the interactions of A166 with ADRP (6W02) are presented in Fig. 3c.

\section{Molecular dynamics (MD) simulation}

The protein-ligand complexes with the shortlisted ligands A104 and A166 were performed by MD simulation study to examine the stability of the compounds to the binding 
Table 2 List of phytocompounds identified and quantified from $H$. cordata by GC-MS

\begin{tabular}{|c|c|c|c|c|}
\hline SL No & Code name & Compound name & Peak area\% & $\begin{array}{l}\text { Molecular } \\
\text { mass }(\mathrm{g} / \mathrm{mol})\end{array}$ \\
\hline 1 & A1 & Propane, 1,1-dimethoxy- & 0.12 & 104.15 \\
\hline 2 & $\mathrm{~A} 2$ & Dimethyl fumarate & 0.20 & 144.12 \\
\hline 3 & A3 & Butanedioic acid, dimethyl ester & 0.53 & 146.14 \\
\hline 4 & A4 & 1,3,7-Octatriene, 3,7-dimethyl-, (E) & 0.25 & 136.23 \\
\hline 5 & A5 & Dimethyl malate & 0.64 & 162.14 \\
\hline 6 & A6 & 1-Nonanol & 0.12 & 144.25 \\
\hline 7 & A7 & Methyl phenylacetate & 0.14 & 150.17 \\
\hline 8 & A8 & cis-4-methoxy thujane & 0.20 & 129.20 \\
\hline 9 & A9 & Nonanoic acid, methyl ester & 0.27 & 172.26 \\
\hline 10 & A10 & 1,1-Dimethoxynonane & 0.16 & 188.31 \\
\hline 11 & A11 & 2-Undecanone & 1.06 & 170.29 \\
\hline 12 & A12 & Methyl Decanoate & 6.88 & 186.29 \\
\hline 13 & A13 & $n$-Decanoic acid & 1.15 & 172.26 \\
\hline 14 & A14 & DL-Proline, 5-oxo-, methyl ester & 0.38 & 143.14 \\
\hline 15 & A15 & Undecanoic acid, methyl ester & 0.15 & 200.32 \\
\hline 16 & A16 & Decanoic acid, TMS derivative & 0.23 & 244.44 \\
\hline 17 & A17 & 14-Bromo-2-methyl-tetradec-1-en-3-ol & 1.23 & 305.29 \\
\hline 18 & A18 & Trimethylsilyl p-(trimethylsilyloxy)benzoate & 0.48 & 282.48 \\
\hline 19 & A19 & Phenol, 2,4-bis(1,1-dimethylethyl)- & 0.32 & 278.50 \\
\hline 20 & $\mathrm{~A} 20$ & Dodecanoic acid, methyl ester & 0.62 & 214.34 \\
\hline 21 & A21 & 1-Hexadecene & 0.21 & 224.42 \\
\hline 22 & A22 & Quinic acid & 1.28 & 192.17 \\
\hline 23 & A23 & gamma-Nonalactone & 0.23 & 156.22 \\
\hline 24 & A24 & Dodecanaldimethylacetal & 1.19 & 230.39 \\
\hline 25 & A25 & Methyl tetradecanoate & 0.39 & 242.40 \\
\hline 26 & A26 & 1-Nonadecene & 0.22 & 266.50 \\
\hline 27 & A27 & $6,10,14$-Trimethylpentadecan-2-one & 0.28 & 268.50 \\
\hline 28 & A28 & Neophytadiene & 0.91 & 278.50 \\
\hline 29 & A29 & 2-Hexadecen-1-ol, 3,7,11,15-tetramethyl-, acetate, (2E,7R,11R)- & 0.44 & 338.60 \\
\hline 30 & A30 & 9-Hexadecenoicacid, methyl ester, (Z)- & 0.45 & 268.40 \\
\hline 31 & A31 & Hexadecanoic acid, methyl ester & 7.69 & 270.50 \\
\hline 32 & A32 & n-Hexadecanoic acid & 4.86 & 256.42 \\
\hline 33 & A33 & Eicosyltrifluoroacetate & 0.28 & 394.60 \\
\hline 34 & A34 & Heptadecanoic acid, methyl ester & 0.24 & 284.50 \\
\hline 35 & A35 & Palmitic Acid, TMS derivative & 0.41 & 328.60 \\
\hline 36 & A36 & 2(3H)-Furanone, 5-heptyldihydro- & 0.26 & 184.27 \\
\hline 37 & A37 & n-Nonadecanol-1 & 3.62 & 284.50 \\
\hline 38 & A38 & 9,12-Octadecadienoic acid (Z, Z)-, methyl ester & 5.37 & 294.47 \\
\hline 39 & A39 & 6-Octadecenoic acid, methyl ester, (Z)- & 7.05 & 296.50 \\
\hline 40 & A40 & cis-11-Octadecenoic acid methyl ester & 0.44 & 296.50 \\
\hline 41 & A41 & 2-Hexadecen-1-ol, 3,7,11,15-tetramethyl-, acetate, (2E,7R,11R) & 4.57 & 338.60 \\
\hline 42 & A42 & Methyl stearate & 3.81 & 298.50 \\
\hline 43 & A43 & 9,12-Octadecadienoic acid (Z, Z)-, methyl ester & 5.37 & 294.47 \\
\hline 44 & A44 & cis-9-Hexadecenal & 1.89 & 238.41 \\
\hline 45 & A45 & Octadec-9-enoic acid & 0.21 & 282.50 \\
\hline 46 & A46 & 1-Octadecanol, TMS derivative & 0.11 & 342.67 \\
\hline 47 & A47 & Octadecanoic acid & 1.02 & 284.50 \\
\hline 48 & A48 & Phytol, TMS derivative & 0.20 & 368.71 \\
\hline 49 & A49 & Ethyl 9,12-hexadecadienoate & 0.28 & 280.40 \\
\hline
\end{tabular}


Table 2 (continued)

\begin{tabular}{|c|c|c|c|c|}
\hline SL No & Code name & Compound name & Peak area $\%$ & $\begin{array}{l}\text { Molecular } \\
\text { mass }(\mathrm{g} / \mathrm{mol})\end{array}$ \\
\hline 50 & A50 & 3.alpha., 5.alpha.-cyclo-ergosta-7,9(11), 22t-triene-6.beta.-ol & 0.30 & 394.63 \\
\hline 51 & A51 & n-Nonadecanol-1 & 1.36 & 284.50 \\
\hline 52 & A52 & 3.alpha., 5.alpha.-cyclo-ergosta-7,9(11), 22t-triene-6.beta.-ol & 0.68 & 394.63 \\
\hline 53 & A53 & 9-Octadecenal, (Z)- & 0.30 & 266.50 \\
\hline 54 & A54 & Eicosanoicacid, methyl ester & 1.12 & 326.60 \\
\hline 55 & A55 & Docosanoic acid, methyl ester & 0.93 & 354.60 \\
\hline 56 & A56 & Tricosanoic acid, methyl ester & 0.44 & 368.60 \\
\hline 57 & A57 & Hexadecanoic acid, 2-hydroxy-, methyl ester & 0.43 & 316.50 \\
\hline 58 & A58 & $\begin{array}{l}\text { 3-Isobutyl-9,10-dimethoxy-2,3,4,6,7,11b-hexahydro-1H-pyrido[2,1-a] } \\
\text { isoquinolin-2-amine }\end{array}$ & 0.30 & 318.50 \\
\hline 59 & A59 & Tetracosanoic acid, methyl ester & 0.80 & 382.70 \\
\hline 60 & A60 & 1-Methyladenine & 0.13 & 281.27 \\
\hline 61 & A61 & Methyl 2-hydroxy-heptadecanoate & 0.24 & 314.50 \\
\hline 62 & A62 & 2H-1,3-Benzoxazine, octahydro-2-(4-methoxyphenyl)-, trans- & 4.00 & 217.31 \\
\hline 63 & A63 & Pentacosanoic acid, methyl ester & 0.14 & 396.70 \\
\hline 64 & A64 & Methyl 2-hydroxy-tetracosanoate & 1.04 & 398.70 \\
\hline 65 & A65 & 1-Hentetracontanol & 0.36 & 593.10 \\
\hline 66 & A66 & 2-Hydroxy-5-methoxybenzaldehyde, 3-methylbutyl ether & 0.43 & 222.28 \\
\hline 67 & A67 & Hexacosanoic acid, methyl ester & 0.32 & 410.70 \\
\hline 68 & A68 & 6,7-Dihydroindoxazene, 3-undecyl & 0.27 & 275.40 \\
\hline 69 & A69 & Spirost-5-en-3-ol, acetate, (3.beta., 25R)- & 0.24 & 456.70 \\
\hline 70 & A70 & Octacosanoic acid, methyl ester & 1.09 & 438.80 \\
\hline 71 & A71 & Ergost-5-en-3-ol, (3.beta., 24R)- & 0.72 & 400.70 \\
\hline 72 & A72 & Stigmasterol & 0.63 & 412.70 \\
\hline 73 & A73 & Diosgenin & 2.26 & 414.60 \\
\hline 74 & A74 & gamma.-Sitosterol & 5.82 & 414.70 \\
\hline 75 & A75 & 9,19-Cyclolanost-24-en-3-ol, (3.beta.)- & 0.98 & 426.70 \\
\hline 76 & A76 & gamma.-Sitostenone & 0.97 & 412.70 \\
\hline 77 & A77 & Silane, (dotriacontyloxy)trimethyl- & 0.67 & 539.00 \\
\hline 78 & A78 & Olean-12-En-28-Oic Acid, 2.Beta., 3.Beta., & 2.93 & 455.70 \\
\hline 79 & A79 & Stigmastane-3,6-dione, (5.alpha.)- & 0.74 & 428.70 \\
\hline 80 & A80 & C(14A)-Homo-27-norgammacer-14-ene, 3.beta.-methoxy & 0.79 & 456.70 \\
\hline
\end{tabular}

site of 6LU7, 7JRN and 6W02 according to their predicted affinity as mentioned in Table 4. MD simulation deals with studying the behavior of protein and ligand for a particular time. The whole simulation was subjected for $100 \mathrm{~ns}$ in the production phase for the ligand complexes. The structure and dynamic properties of the protein-ligand complexes were analyzed as the backbone RMSDs during the simulation period of $100 \mathrm{~ns}$. The RMSD plot for 6LU7 and 6LU7 bounded with A104 presented in Fig. 4a reveals that during the initial $60 \mathrm{~ns}$ of MD simulation, the ligand-bound protein showed significant stability, however, it was slightly unstable after $60 \mathrm{~ns}$ of simulation. Similarly, RMSD plot of 7JRN and 7JRN bonded with A104 is presented in Fig. 4b, where the ligand-bound complex established a stabilization between 50 and $70 \mathrm{~ns}$ of simulation. However, the RMSD plot 6W02 bonded with A166 presented in Fig. 4c showed instability from 0 to $19 \mathrm{~ns}$ of simulation, and after $20 \mathrm{~ns}$, it became stabilized up to $30 \mathrm{~ns}$. Although a slight deviation was observed between 30 and $60 \mathrm{~ns}$, the complexes stabilized after $60 \mathrm{~ns}$.

Ligand RMSD, the radius of Gyration (rGyr), Molecular Surface Area (MolSA), Solvent Accessible Surface Area (SASA), Polar Surface Area (PSA) of ligands with respect to the reference conformation were also studied during the MD simulation which is presented in Fig. 5a-c.

The root-mean-square fluctuations (RMSF) were assessed and plotted to equate the flexibility of each residue in the ligand-protein complexes. The RMSF of the protein-ligand complex denoted the minimized fluctuation for all the complexes. The RMSF did not deviate much during the simulation period of $100 \mathrm{~ns}$, and the average RMSF values were kept constant for all the complexes and the same is presented in Fig. 6a-c. 
Fig. 1 GC-MS chromatogram (80) of phytocompounds quantified from $H$. cordata

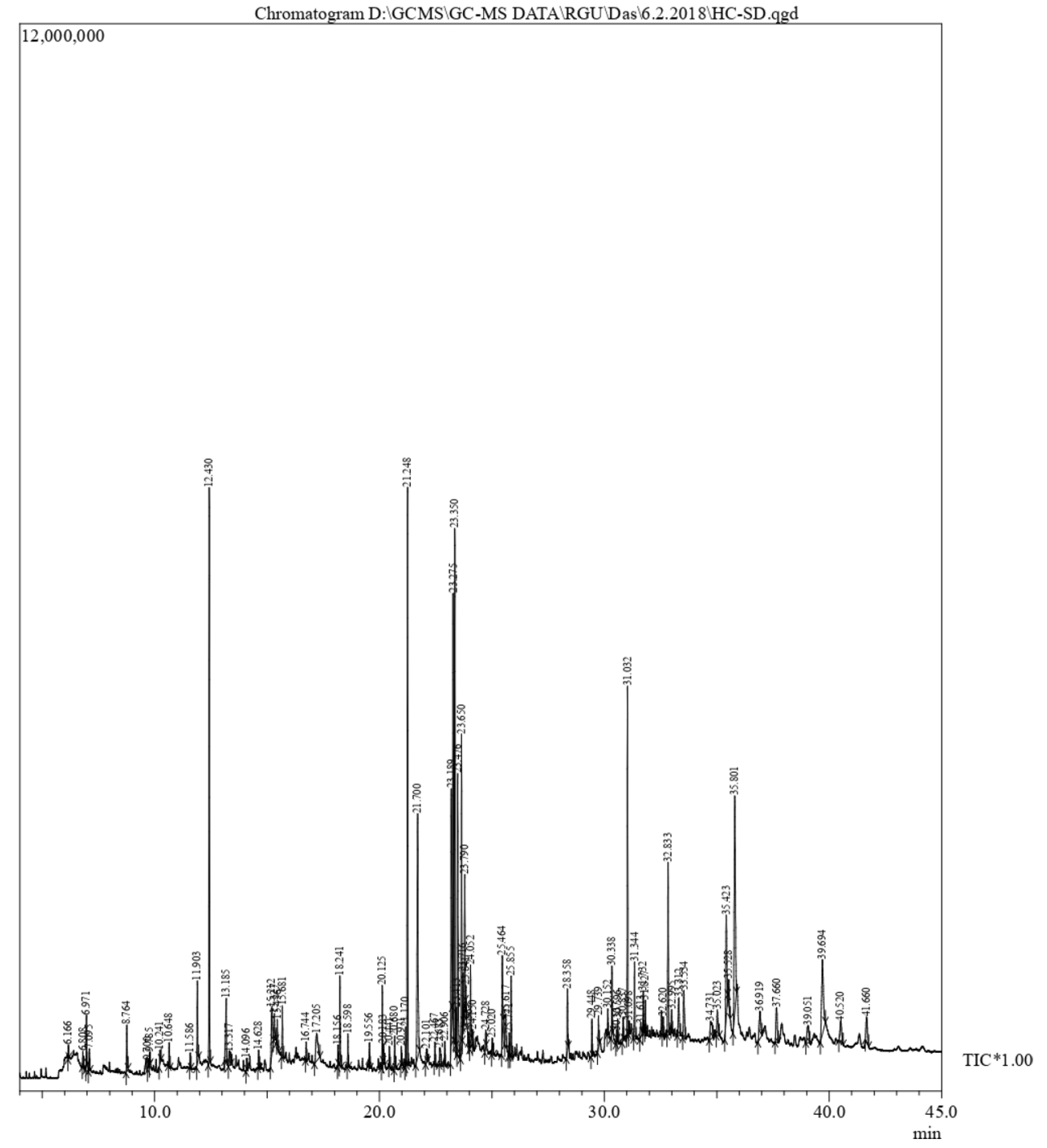

The hydrogen bond interaction between the bioactive compounds and the active site residues of the proteins was also analyzed during the entire duration of simulation. For 6LU7 and A104, H-bond was observed in His-163; 7JRN and A104 in ASN-167 and GLN-269 and 6W02 and A166 in ASP-22, LEU-126, ALA-129, ILE-131 and ALA-154 and are presented in Fig. $7 \mathrm{a}-\mathrm{c}$ along with other interactions formed during the $100 \mathrm{~ns}$ of simulation.

Result of the interaction study between the shortlisted ligands and the receptor proteins at various steps of the Molecular Dynamics simulation is reported in Figs. 7a-c and $8 \mathrm{a}-\mathrm{c}$. Fig. $7 \mathrm{a}-\mathrm{c}$ demonstrates the Protein interactions with the ligand observed throughout the simulation. Receptor-ligand interactions are generally categorized into four types viz. Hydrogen Bonds, Hydrophobic, Ionic and Water Bridges. Each interaction type contains more specific subtypes, which were also explored through the 'Simulation Interactions Diagram' presented in Fig. 8a-c. The stacked bar charts are normalized over the course of the trajectory, for example, a value of 0.5 suggests that $50 \%$ of the simulation time, the specific interaction is maintained. Values over 1.0 are possible as some protein residue makes multiple contacts of same subtype with the ligand. Timeline representation of the interactions and contacts (H-bonds, Hydrophobic, Ionic, Water bridges) is also summarized in each of the lower panel of Fig. 7a-c. The interaction analysis between 6LU7 and A104 during the entire duration of $100 \mathrm{~ns}$ of MDs shows that the amino acid His 163, His 164, Glu 166, Asp 187, Arg-188, Thr 190 and Gln 192 have formed hydrogen bonds with different atoms of A104. Similarly, Asn 267, Gly 266 and Gln 269 of 7JRN have shown hydrogen bond contacts with the ligand A104. Lastly, the interaction analysis between 6W02 and A166 reveals that hydrogen bonds were formed between the ligand with amino acids namely Ala 22, Ile 23, Leu 126, Ser 128, Ala 129, Ile 131, Ala 154 and Phe 156. 
Table 3 List of phytocompounds identified from $H$. cordata by LC-MS

\begin{tabular}{|c|c|c|c|}
\hline Sl. No & Code name & Compound name & $\begin{array}{l}\text { Molecular } \\
\text { mass }(\mathrm{g} / \mathrm{mol})\end{array}$ \\
\hline 1 & A81 & 3-methyl sulfolene & 132.02 \\
\hline 2 & A82 & Niacinamide & 122.05 \\
\hline 3 & A83 & 3-Oxo-3-ureidopropanoate & 146.03 \\
\hline 4 & A84 & S-(4,5-Dihydro-2-methyl-3-furanyl) ethanethioate & 138.04 \\
\hline 5 & A85 & Urocanic acid & 138.04 \\
\hline 6 & A86 & 3-hydroxy-3-methyl-Glutaric acid & 162.05 \\
\hline 7 & A87 & Magnesium dipropionate & 170.04 \\
\hline 8 & A88 & 1-Naphthoic acid & 172.05 \\
\hline 9 & A89 & 2-Ketogulonolactone & 176.03 \\
\hline 10 & A90 & Dibenzo-p-dioxin & 184.05 \\
\hline 11 & A91 & p-Hydroxybenzophenone & 198.06 \\
\hline 12 & A92 & ethyl-2-amino-4-methyl-Thiazole-5-Carboxylate & 186.04 \\
\hline 13 & A93 & Dinitrosopentamethylenetetramine & 186.08 \\
\hline 14 & A94 & N $\alpha$-Acetyl-L-glutamine & 188.08 \\
\hline 15 & A95 & Porphobilinogen & 226.09 \\
\hline 16 & A96 & (2Z,4'Z)-2-(5-Methylthio-4-penten-2-ynylidene)-1,6-dioxaspiro[4.4]non-3-ene & 234.07 \\
\hline 17 & A97 & Clofibric Acid & 214.03 \\
\hline 18 & A98 & N-Glycolyl-D-glucosamine & 237.08 \\
\hline 19 & A99 & 2-(7'-Methylthio)heptylmalic acid & 278.11 \\
\hline 20 & A100 & 8-Hydroxydesmethylondansetron & 295.13 \\
\hline 21 & A101 & L-N-(1H-Indol-3-ylacetyl)aspartic acid & 290.09 \\
\hline 22 & A102 & Purpuritenin B & 292.11 \\
\hline 23 & A103 & Tuliposide B & 294.09 \\
\hline 24 & A104 & 6-Hydroxyondansetron & 309.15 \\
\hline 25 & A105 & Demethylcitalopram & 310.15 \\
\hline 26 & A106 & Ethopropazine & 312.17 \\
\hline 27 & A107 & Fluvoxamine acid & 318.12 \\
\hline 28 & A108 & podocarpic acid & 274.16 \\
\hline 29 & A109 & Cinnavalininate & 300.03 \\
\hline 30 & A110 & Diazinon & 304.10 \\
\hline 31 & A111 & Laurencenone A & 332.05 \\
\hline 32 & A112 & Maximaisoflavone $\mathrm{J}$ & 336.14 \\
\hline 33 & A113 & 1,3-Diaza-spiro[4.6]undecane-2,4-dione & 316.19 \\
\hline 34 & A114 & 2'-Oxoquinidine & 340.18 \\
\hline 35 & A115 & Isocycloneosamandaridine & 345.23 \\
\hline 36 & A116 & 9-hydroperoxy-12,13-dihydroxy-10-octadecenoic acid & 346.23 \\
\hline 37 & A117 & 5alpha-Androstane-2beta-fluoro-17beta-ol-3-one acetate & 350.22 \\
\hline 38 & A118 & Lochnericine & 352.18 \\
\hline 39 & A119 & Tephrowatsin A & 354.18 \\
\hline 40 & A120 & Kanzonol V & 376.16 \\
\hline 41 & A121 & 5(S),6(R)-Lipoxin A4-d5 & 357.25 \\
\hline 42 & A122 & 10-Deoxygeniposidic acid & 358.12 \\
\hline 43 & A123 & Malachite green & 364.17 \\
\hline 44 & A124 & 6alpha,9-Difluoro-11beta-hydroxypregn-4-ene-3,20-dione & 366.20 \\
\hline 45 & A125 & 9,10-dihydroxy-Octadecanedioic acid & 346.23 \\
\hline 46 & A126 & Gentian Violet & 371.24 \\
\hline 47 & A127 & 15beta-Hydroxy-7alpha-mercapto-pregn-4-ene-3,20-dione 7 -acetate & 404.20 \\
\hline 48 & A128 & Albafuran A & 378.18 \\
\hline 49 & A129 & Fludrocortisone & 380.20 \\
\hline
\end{tabular}


Table 3 (continued)

Sl. No Code name Compound name

Molecular

mass $(\mathrm{g} / \mathrm{mol})$

\begin{tabular}{|c|c|c|c|}
\hline 50 & A130 & Ajaconine & 359.24 \\
\hline 51 & A131 & 3,12-Dioxochola-1,4,9(11)-trien-24-oic Acid & 382.21 \\
\hline 52 & A132 & Quercetol B & 368.19 \\
\hline 53 & A133 & 5-Megastigmen-7-yne-3,9-diol 9-glucoside & 370.19 \\
\hline 54 & A134 & Pirenperone & 393.18 \\
\hline 55 & A135 & 2,2-Dimethyl-3-(4-methoxyphenyl)-4-ethyl-6-(1-pyrrolidinylmethyl)-2H-1-benzopyran-7-ol & 393.23 \\
\hline 56 & A136 & 20-Dihydrodexamethasone & 394.22 \\
\hline 57 & A137 & 12 $\alpha$-Hydroxy-3-oxochola-1,4,6-trien-24-oic Acid & 384.23 \\
\hline 58 & A138 & Actinonin & 385.25 \\
\hline 59 & A139 & trans-Methylbixin & 408.23 \\
\hline 60 & A140 & Sesamin & 354.35 \\
\hline 61 & A141 & Pregn-4-en-20-one,3b,17-dihydroxy-6a-methyl-,17-acetate & 388.26 \\
\hline 62 & A142 & $\mathrm{N}$-Carboxytocainideglucuronide & 412.15 \\
\hline 63 & A143 & $3 \beta$-Hydroxy-6-oxo-5 $\alpha$-cholan-24-oic Acid & 390.28 \\
\hline 64 & A144 & Linopirdine & 391.17 \\
\hline 65 & A145 & Naltrindole & 414.19 \\
\hline 66 & A146 & Fluorometholone 17 -acetate & 418.21 \\
\hline 67 & A147 & Tris(butoxyethyl)phosphate & 398.24 \\
\hline 68 & A148 & 4-Quinolone-3-Carboxamide CB2 Ligand & 422.25 \\
\hline 69 & A149 & Myriocin & 401.27 \\
\hline 70 & A150 & $1 \alpha, 25$-dihydroxy-21-nor-20-oxavitamin D3/1 $\alpha, 25$-dihydroxy-21-nor-20-oxacholecalciferol & 404.29 \\
\hline 71 & A151 & Usambarensine & 432.23 \\
\hline 72 & A152 & 5,5'-(4-Tetradecene-1,4-diyl)bis[1,3-benzenediol]; 5,5'-[(4Z)-4-Tetradecene-1,14-diyl]di(1,3-benzenediol) & 412.26 \\
\hline 73 & A153 & 6-keto Testosterone Enanthate & 414.28 \\
\hline 74 & A154 & Clindamycin sulfoxide & 440.17 \\
\hline 75 & A155 & Suillin & 440.29 \\
\hline 76 & A156 & 1-heptadecanoyl-sn-glycerol 3-phosphate & 424.26 \\
\hline 77 & A157 & Condelphine & 449.28 \\
\hline 78 & A158 & cholest-4,14-dien-15,20-diol-3,16-dione & 428.29 \\
\hline 79 & A159 & Dihydrocelastrol & 452.29 \\
\hline 80 & A160 & Ceanothenic acid & 454.31 \\
\hline 81 & A161 & 17-phenyl trinor Prostaglandin F2 $\alpha$ serinol amide & 461.28 \\
\hline 82 & A162 & 26,26,26-trifluoro-25-hydroxy-27-norvitamin D3/26,26,26-trifluoro-25-hydroxy-27-norcholecalciferol & 442.31 \\
\hline 83 & A163 & Isoquercitrin & 464.40 \\
\hline 84 & A164 & 3,5-Didecanoylpyridine & 387.60 \\
\hline 85 & A165 & Quercetin & 302.25 \\
\hline 86 & A166 & Quercitrin & 484.40 \\
\hline 87 & A167 & Hyperoside & 464.41 \\
\hline 88 & A168 & Amastatin & 474.27 \\
\hline 89 & A169 & Progeldanamycin & 475.29 \\
\hline 90 & A170 & 26,26,26-trifluoro-25-hydroxyvitamin D3/26,26,26-trifluoro-25-hydroxycholecalciferol & 454.31 \\
\hline 91 & A171 & Callystatin A & 456.32 \\
\hline 92 & A172 & Borrelidin & 489.31 \\
\hline 93 & A173 & Murrayenol & 470.34 \\
\hline 94 & A174 & Dipyridamole & 504.32 \\
\hline 95 & A175 & Rhodoxanthin & 562.38 \\
\hline 96 & A176 & Canthaxanthin & 564.39 \\
\hline 97 & A178 & 3-Benzoyloxy-6-oxo-12-ursen-28-oic acid & 574.36 \\
\hline
\end{tabular}

Bold words signify main compound's potential to inhibit SARS-CoV-2 replication proteins 


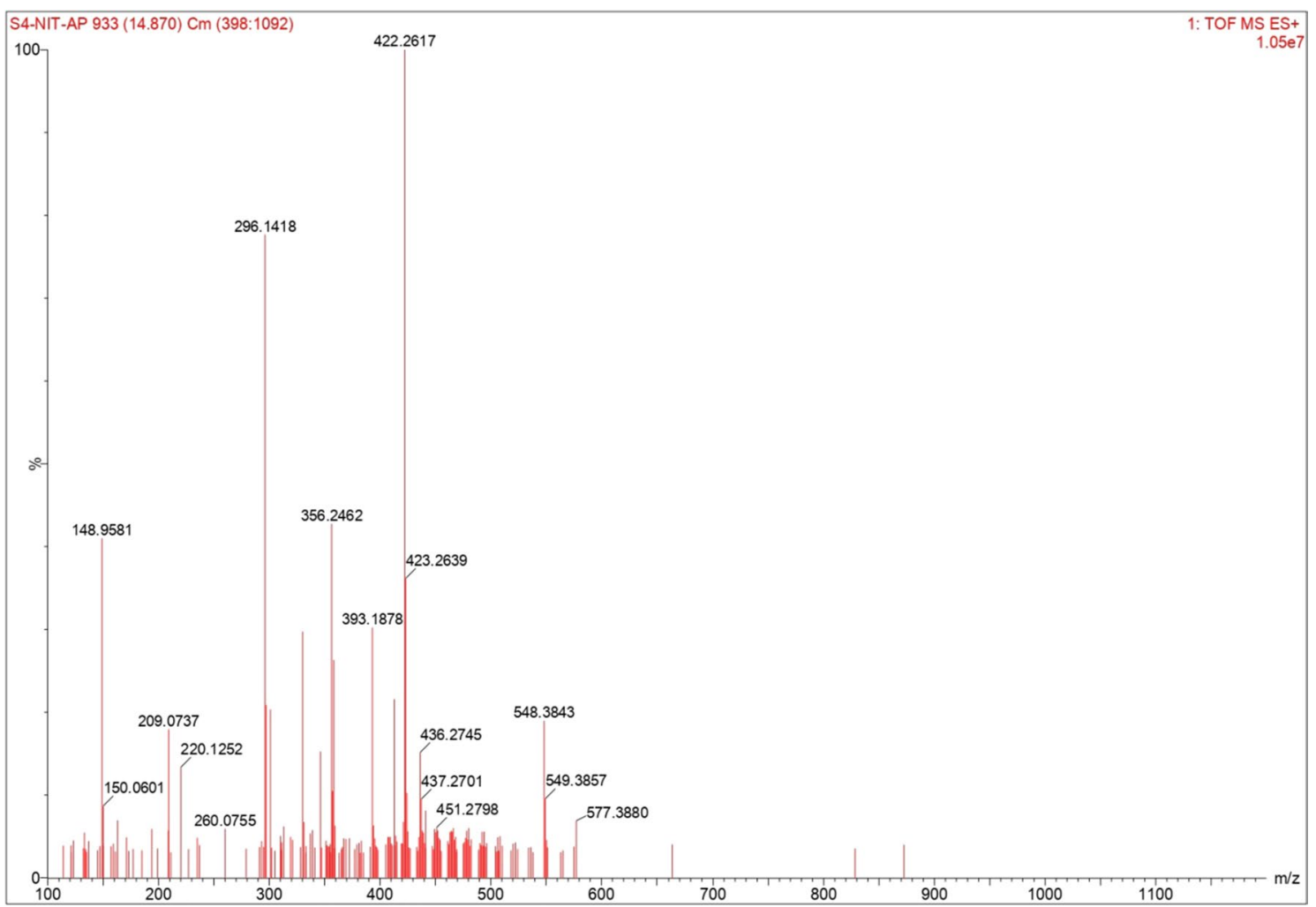

Fig. 2 LC-MS chromatogram of phytocompounds identified from H. cordata

Table 4 Result of the docking experiment performed between the receptors and the ligand library

\begin{tabular}{|c|c|c|c|c|c|c|}
\hline Compounds code & Compounds name & Docking score & $\begin{array}{l}\text { Glide ligand } \\
\text { efficiency }\end{array}$ & Glide gscore & Glide lipo & Glide hbond \\
\hline \multicolumn{7}{|c|}{ Result of Docking between $6 L U 7$ and the ligand library } \\
\hline A107 & Fluvoxamine acid & -7.929 & -1.01 & -7.929 & -2.108 & -0.36 \\
\hline A104 & 6-Hydroxyondansetron & -7.147 & -0.884 & -7.274 & -2.472 & -0.122 \\
\hline A120 & Kanzonol V & -7.024 & -0.762 & -7.024 & -3.279 & -0.588 \\
\hline A127 & $\begin{array}{l}\text { 15beta-Hydroxy-7alpha-mercapto- } \\
\text { pregn-4-ene-3,20-dione 7-acetate }\end{array}$ & -6.793 & -0.737 & -6.793 & -2.162 & -0.304 \\
\hline A99 & 2-(7'-Methylthio) heptylmalic acid & -6.746 & -0.834 & -6.883 & -2.181 & -0.048 \\
\hline \multicolumn{7}{|c|}{ Result of Docking between $7 J R N$ and the ligand library } \\
\hline A105 & Demethylcitalopram & -5.842 & -1.413 & -5.843 & -1.943 & -0.2 \\
\hline A140 & Sesamin & -5.779 & -1.357 & -5.779 & -2.961 & 0 \\
\hline A104 & 6-Hydroxyondansetron & -5.544 & -1.341 & -5.672 & -2.087 & $\mathbf{0}$ \\
\hline A100 & 8-Hydroxydesmethylondansetron & -5.464 & -1.321 & -5.602 & -1.83 & -0.164 \\
\hline A106 & Ethopropazine & -5.226 & -1.277 & -5.227 & -2.377 & 0 \\
\hline \multicolumn{7}{|c|}{ Result of Docking between 6 W02 and the ligand library } \\
\hline A166 & (Quercitrin) & -6.759 & -0.211 & -6.788 & -1.841 & -0.162 \\
\hline A165 & (Quercetin) & -6.067 & -0.276 & -6.099 & -2.301 & 0 \\
\hline A163 & (Isoquercitrin) & -5.674 & -0.172 & -5.703 & -1.815 & 0 \\
\hline A167 & (Hyperoside) & -5.674 & -0.172 & -5.703 & -1.815 & 0 \\
\hline A164 & (3,5-Didecanoylpyridine) & -5.206 & -0.186 & -5.206 & -3.108 & -0.158 \\
\hline
\end{tabular}

Bold words signify main compound's potential to inhibit SARS-CoV-2 replication proteins 
Fig. 3 Interaction diagram with $\mathrm{H}$-bonds and other interactions of a 6LU7 with A104 b 7JRN with A104 c 6W02 with A166 showing different polar and non-polar interactions and bonds
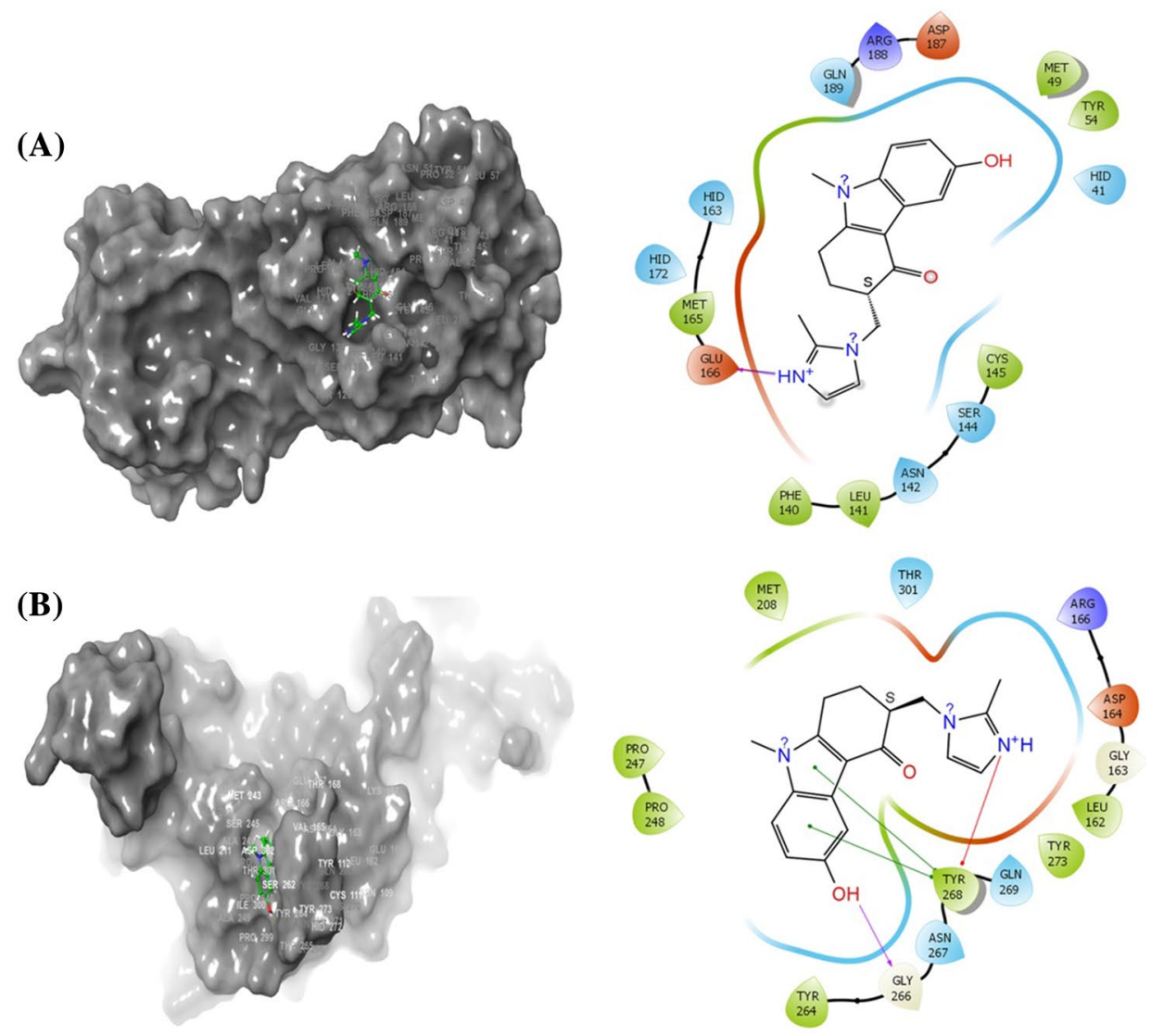

(C)
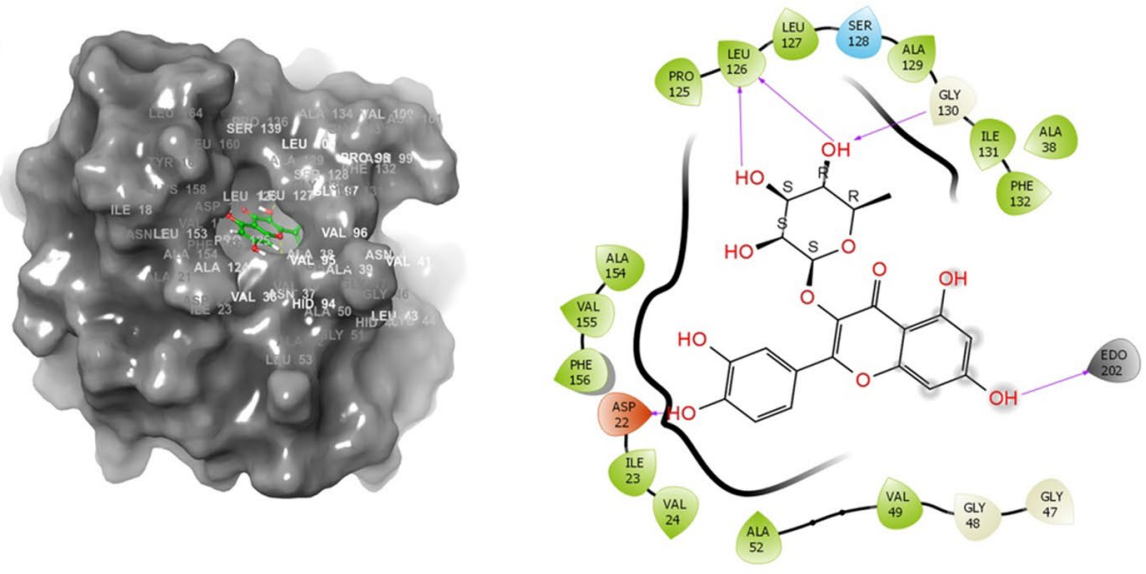
Charged (negative)
Charged (positive)
Glycine
Hydrophobic
Metal

Polar

Unspecified residue

Water

Hydration site

- Metal coordination

\section{ADME-Tox study}

SwissADME server was used to study the ADME-Tox properties of A104 (6-Hydroxyondansetron) and A166 (Quercitrin), and the results are presented in Table 5:

\section{Discussion}

Bioinformatics tools and techniques are widely used in drug discovery sector. In silico-based drug design is an approach which plays an important role in modern drug discovery. 
Fig. 4 a RMSD plot of 6LU7 and 6LU7 bounded with A104. b RMSD plot of 7JRN and 7JRN bonded with A104. c RMSD plot 6W02 and 6W02 bonded with A166

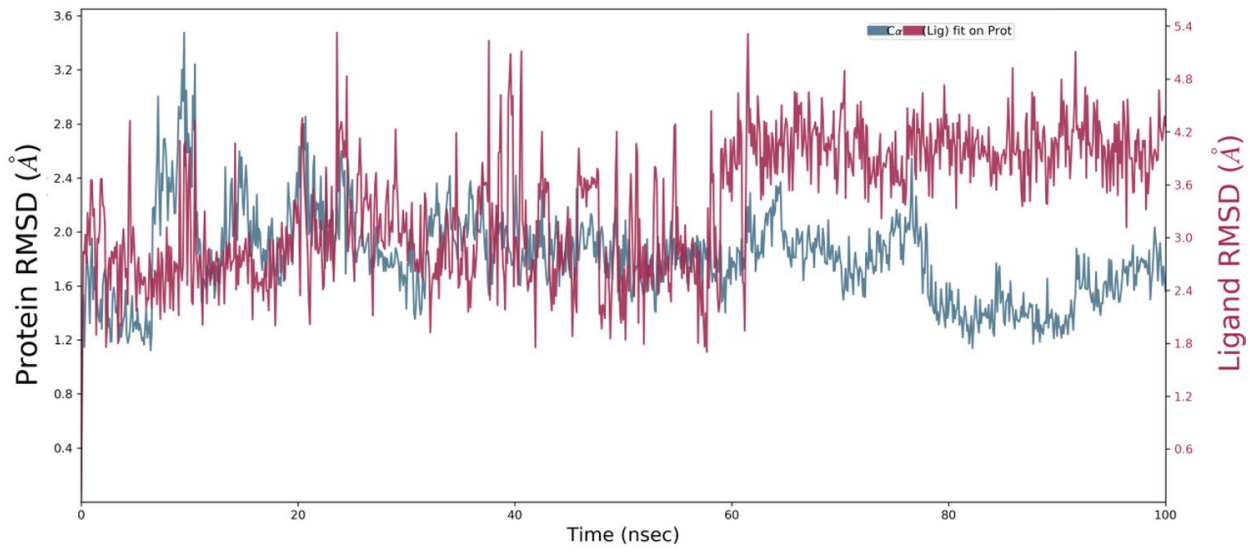

(A) RMSD plot of 6LU7 and 6LU7 bounded with A104

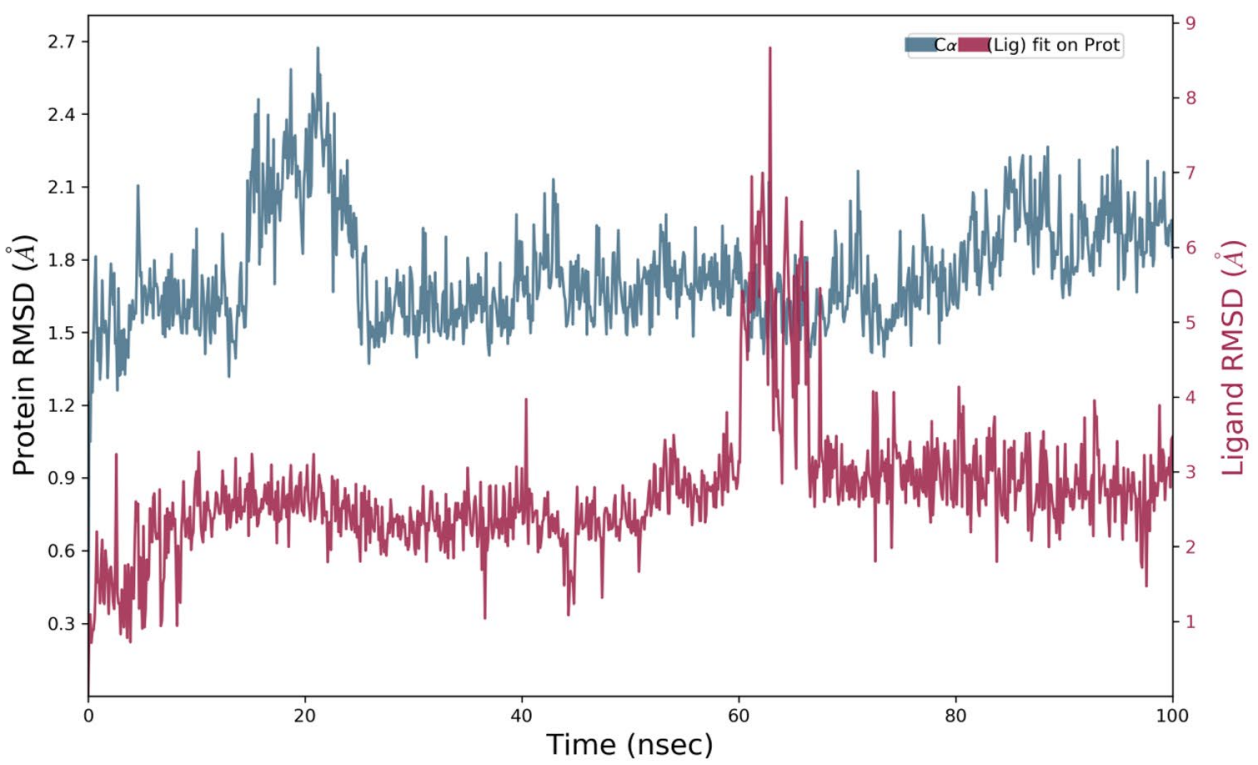

(B) RMSD plot of 7JRN and 7JRN bonded with A104

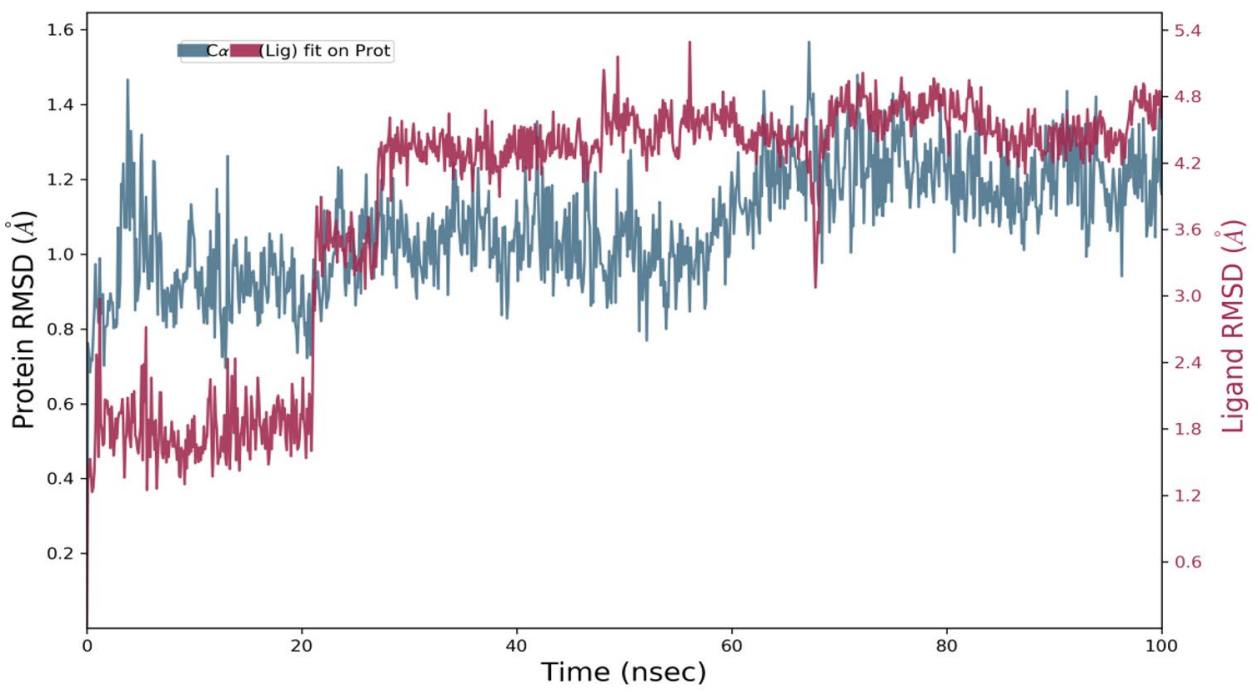

(C) RMSD plot 6W02 and 6W02 bonded with A166 
Fig. 5 Ligand RMSD: Rootmean-square deviation of ligands with respect to the reference conformation. The radius of Gyration (rGyr): Representation of the 'extendedness' of the ligands. Molecular Surface Area (MolSA): Molecular surface calculation with $1.4 \AA$ probe radius. This value is reciprocal to a van der Waals surface area. Solvent Accessible Surface Area (SASA): Surface area of the respective ligands accessible by a water molecule is presented. Polar Surface Area (PSA): Solvent accessible surface area in the ligands contributed only by oxygen and nitrogen atoms. a A104 complexed with 6LU7 b A104 complexed with 7JRN and $\mathbf{c}$ A166 with 6W02
(A)

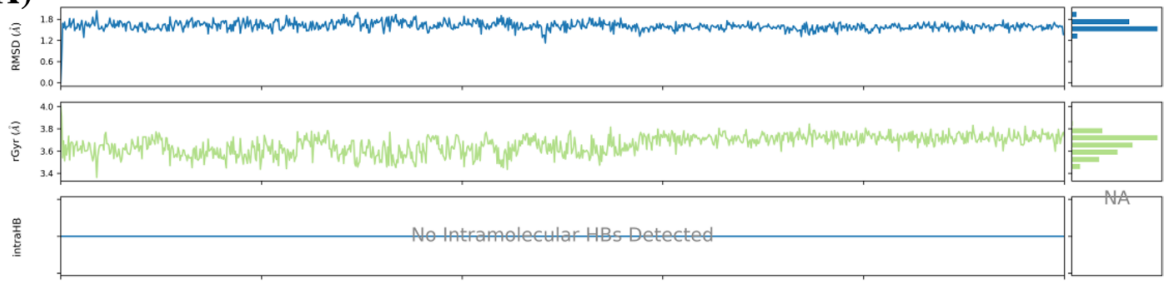

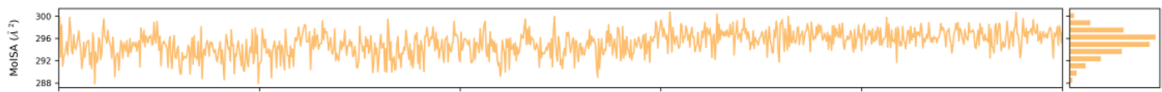

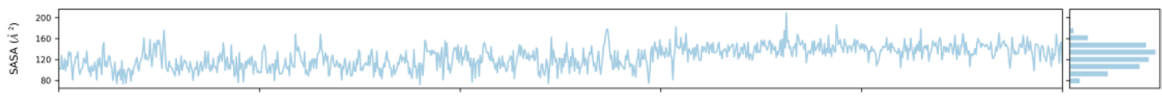

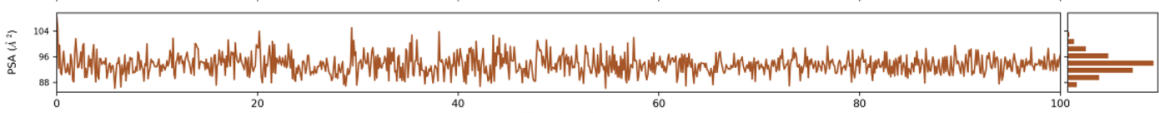

(B)
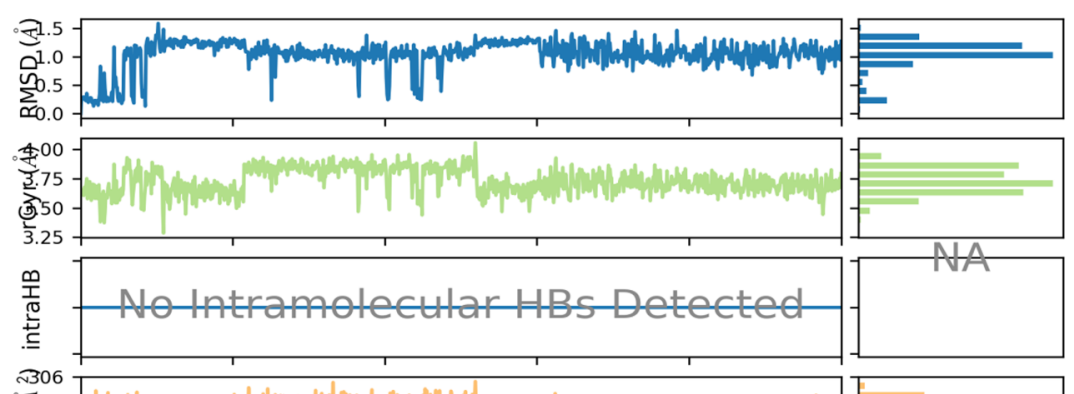

ง306

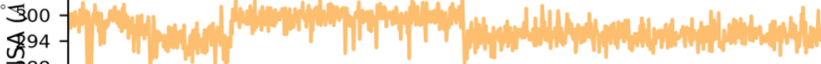

త్రి8

$\sum_{2}^{2} 40$

$+200-$

需 60

120

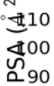

(C)
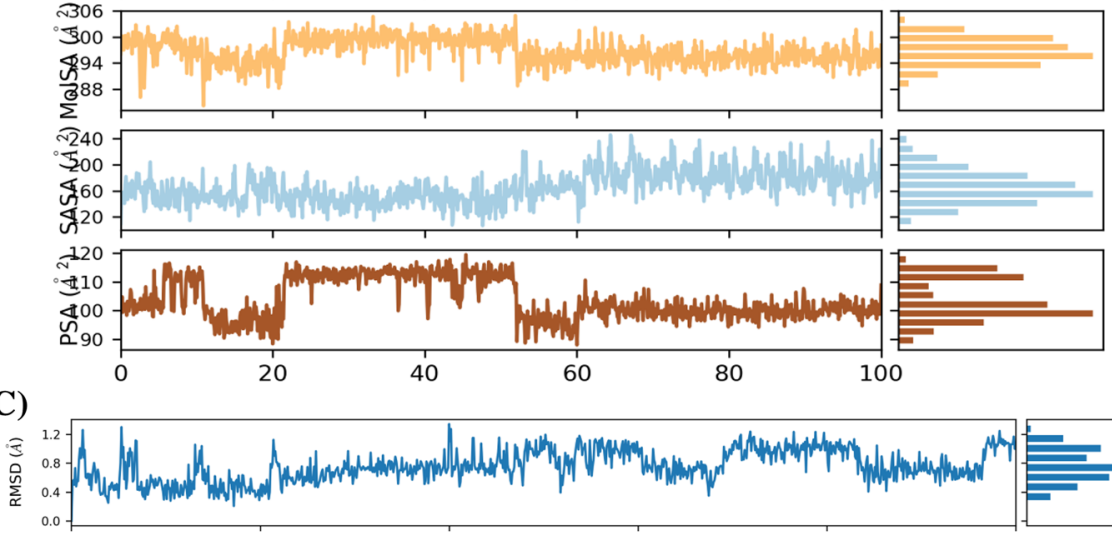

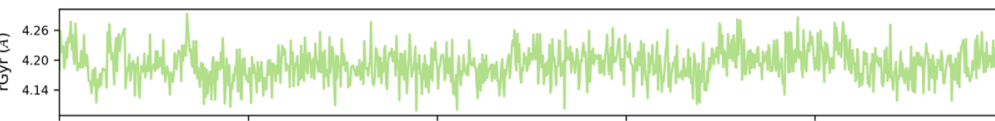
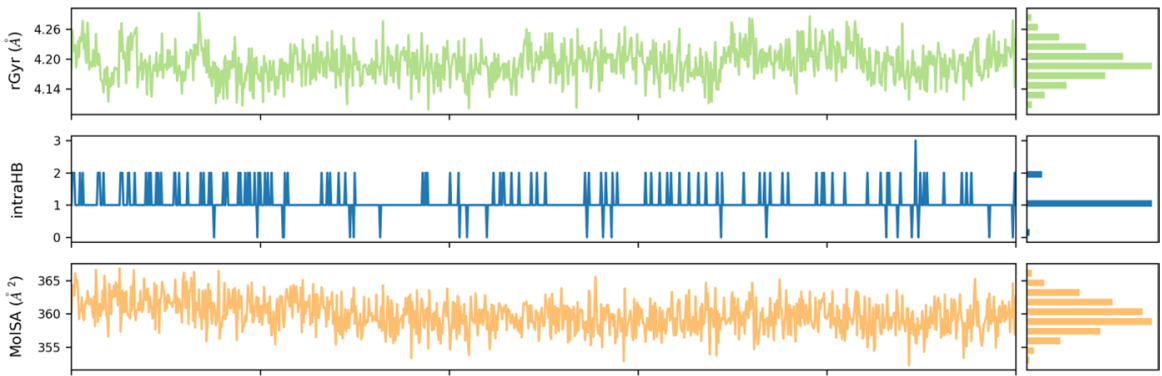

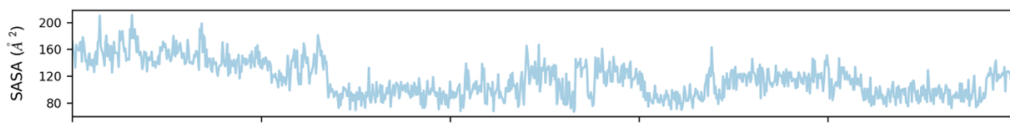

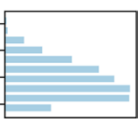

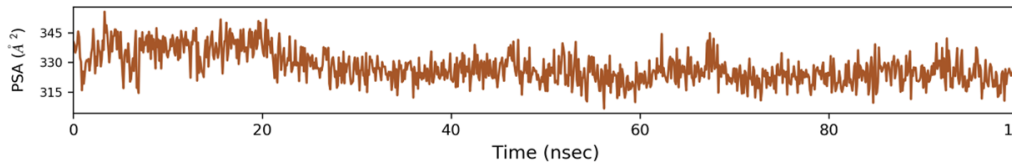

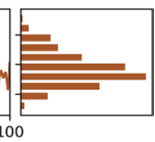


Fig. 6 RMSF plots for Protein a RMSF plot for 6LU7 b RMSF plot for 7JRN c RMSF 6W02

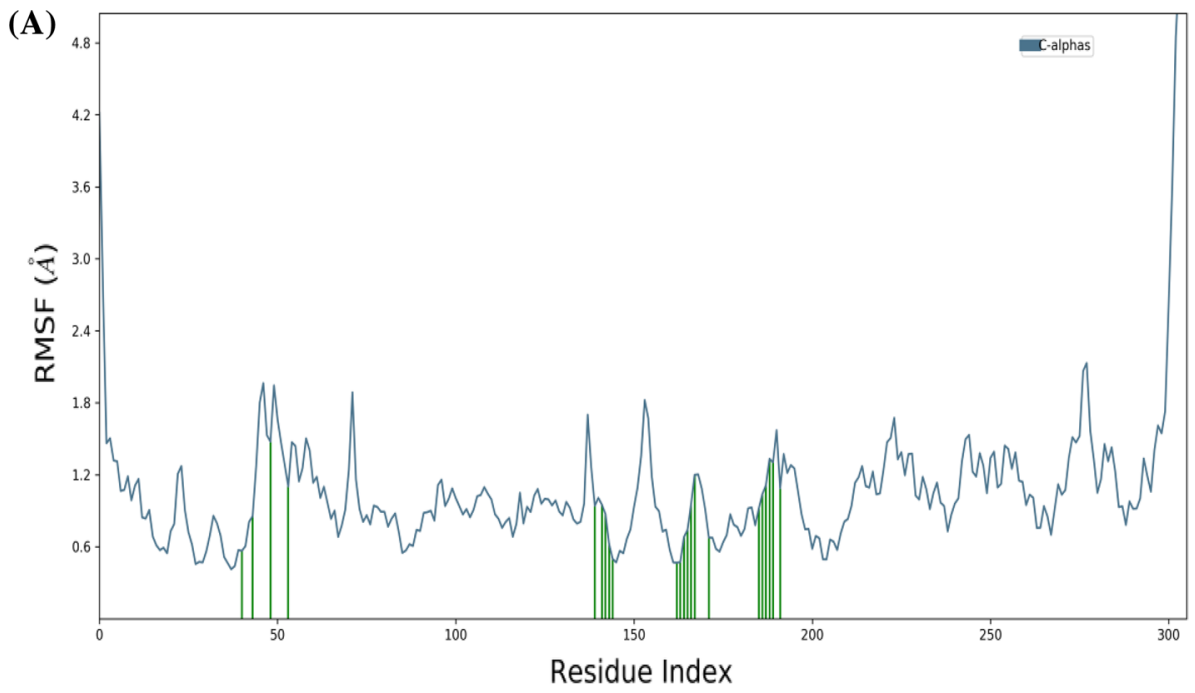

(B)

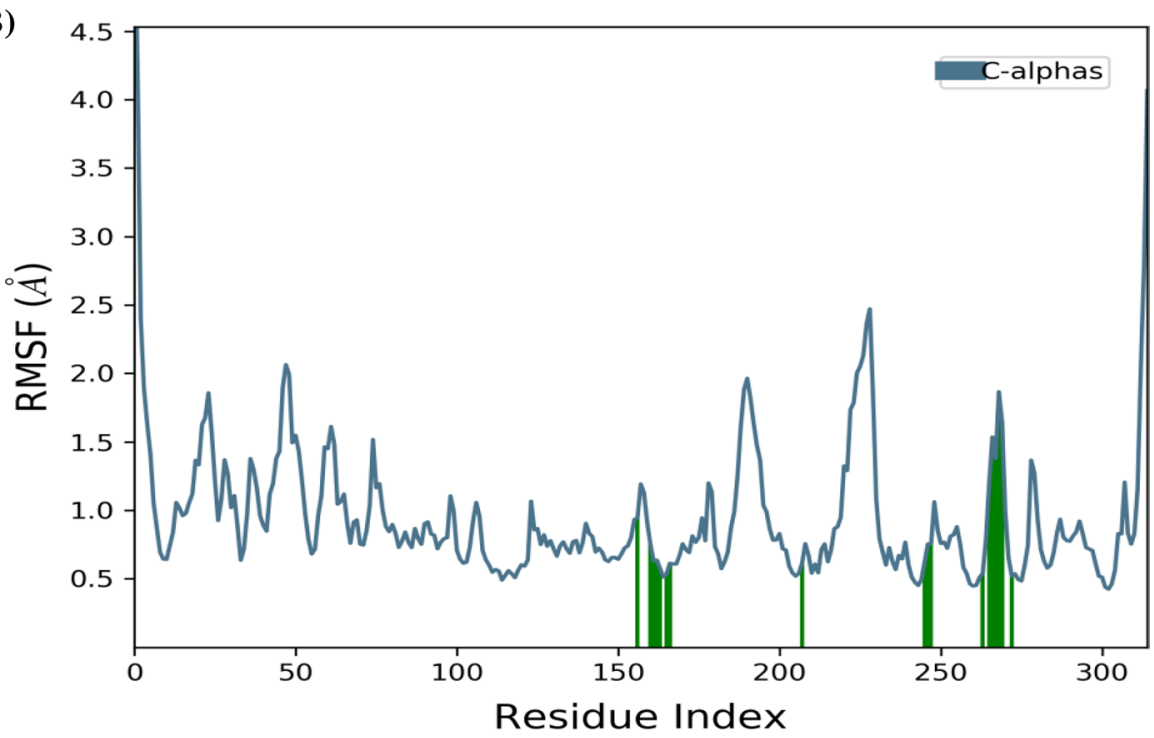

(C)

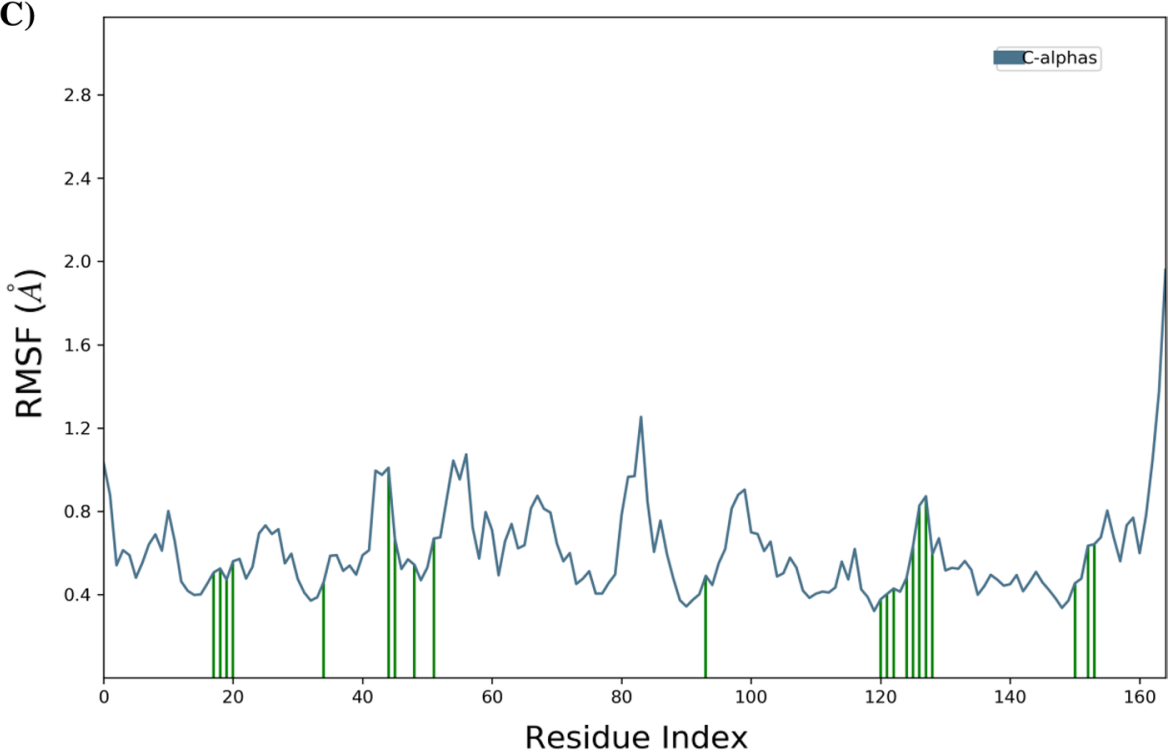



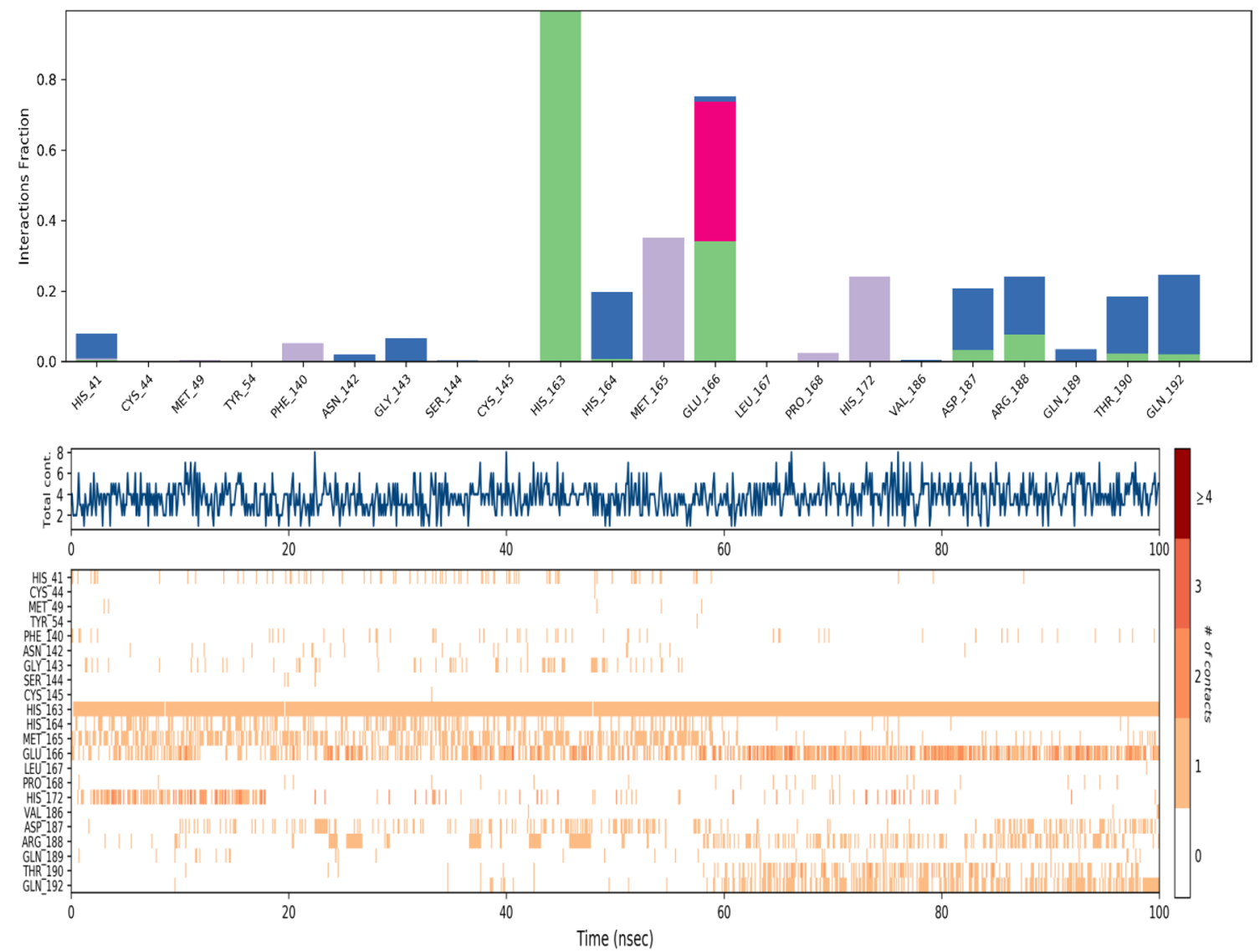

(A) Various interactions between 6LU7 and A104

Fig. 7 a Various interactions between 6LU7 and A104. b Various interactions between 7JRN and A104. c Various interactions between 6W02 and A166

It reduces the cost and takes less time to search out lead molecules. This structural-based drug designing study provides the probable drug compound for a particular disease which can be further confirmed by in vivo, as well as in vitro experimental studies [40, 41]. The outbreak of COVID-19 caused by SARS-CoV-2 has thrown millions of human lives out of gear within one year timescale. The virus has not only disrupted the global healthcare networks but it also severely affected the global economy [42]. Therefore, there is an urgent need of antiviral drugs from bioactive phytocompounds for the inhibition of SARS-CoV-2 replication proteins. The SARS-CoV-2 is a single-stranded RNA virus which requires mainly three proteins, namely Main protease (Mpro), Papain-like protease (PLpro) and ADP ribose phosphatase (ADRP), for their replication. The inhibition of the expression of these proteins may lead to the development of potent antiviral effective against treatment of COVID19. Bioactive phytocompounds from traditional medicinal plants are reported to possess several therapeutic properties. In the present study, we explored the possibilities and demonstrated that at least two bioactive phytocompounds, namely 6-Hydroxyondansetron (Fig. 9a) and Quercitrin (Fig. 9b), quantified from Houttuynia cordata Thunb. possess potential anti-SARS-CoV-2 activities and demonstrated potential to inhibit Main protease (Mpro), Papain-like protease (PLpro) and ADP ribose phosphatase (ADRP). Previous study reported that the extract of $H$. cordata inactivates SARS-CoV 3CL Pro and inhibits the viral replication [9]. It also demonstrated antiviral activity against Chikungunya viral strains [18], Herpes simplex viruses-1 (HSV-1) and Herpes simplex viruses-2 (HSV-2) [21], and dengue virus serotype 2 (DEN-2) [24]. The bioactive phytocompounds isolated from the herb, rutin ( $8.8 \%)$, hyperin $(26.7 \%)$, isoquercitrin (9.9\%), and quercitrin (31.7\%) reduced influenza A virus (IAV)-induced acute lung injury (ALI) in mice by inhibiting Influenza neuraminidase and Toll-like receptor signaling [25]. Our present studies have characterized and identified a total of 177 phytocompounds from the herb $H$. cordata by GC-MS and LC-MS analysis. The molecular docking of ligands (bioactive phytocompounds from $H$. cordata) against three different receptors of SARS-CoV-2, namely Mpro (PDB IDs 6LU7), PLpro (7JRN) and ADRP 

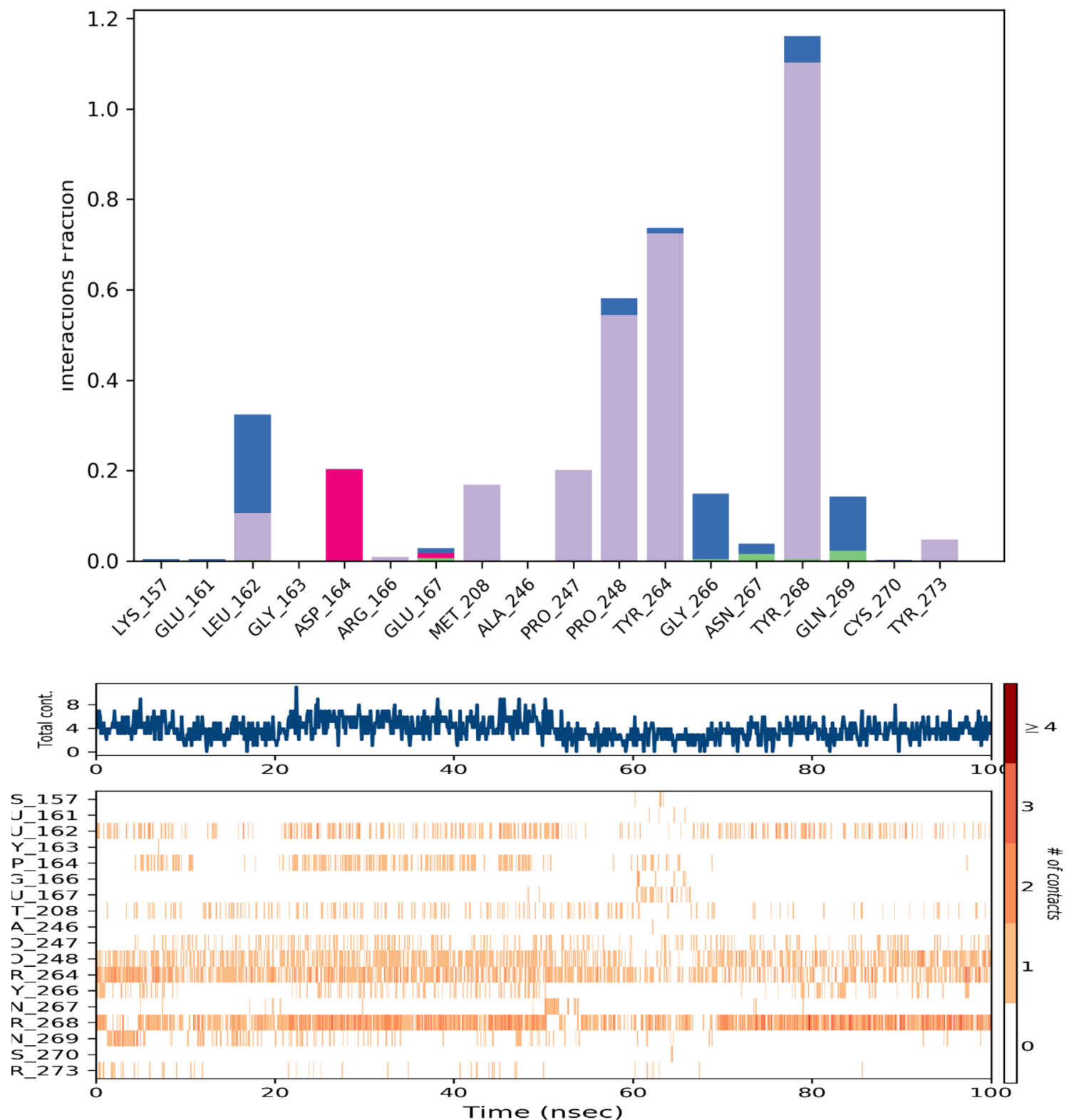

(B) Various interactions between 7JRN and A104

Fig. 7 (continued)

(6W02), respectively, revealed that the bioactive phytocompounds (ligand) coded with A104 (6-Hydroxyondansetron) have shown more binding affinities toward Mpro (6LU7) and PLpro (7JRN) with G-score - 7.274 and -5.672 , respectively, while bioactive phytocompound A166 (Quercitrin) has demonstrated the best binding affinity toward ADRP (6W02) with G-score -6.788 . Therefore, the molecular dynamics simulation study of both the bioactive phytocompounds A104 and A166 was performed. From the MD simulation analysis, it is evident that the complexes A1046LU7 and A166-6W02 have shown better stability than the A104-7JRN complex within $100 \mathrm{~ns}$ duration. The interaction analysis during the entire duration of MDs, as presented in Fig. $7 \mathrm{a}-\mathrm{c}$ and Fig. 8a-c, and its subsequent analysis also support good binding efficiency of the selected ligands to the receptor proteins. MDs study ultimately identified and confirmed A104 and A166 as potential inhibitors for Mpro, PLpro and ADRP which can prevent replication machinery of SARS-CoV-2. ADME-Tox study also reveals that the bioactive phytocompound A104 (6-Hydroxyondansetron) passes all the required drug discovery rules and possesses multi-target capabilities which can become a potential inhibitor for the Mpro (6LU7) and PLpro (7JRN) protein of SARS-CoV-2 without causing toxicity with minimum 

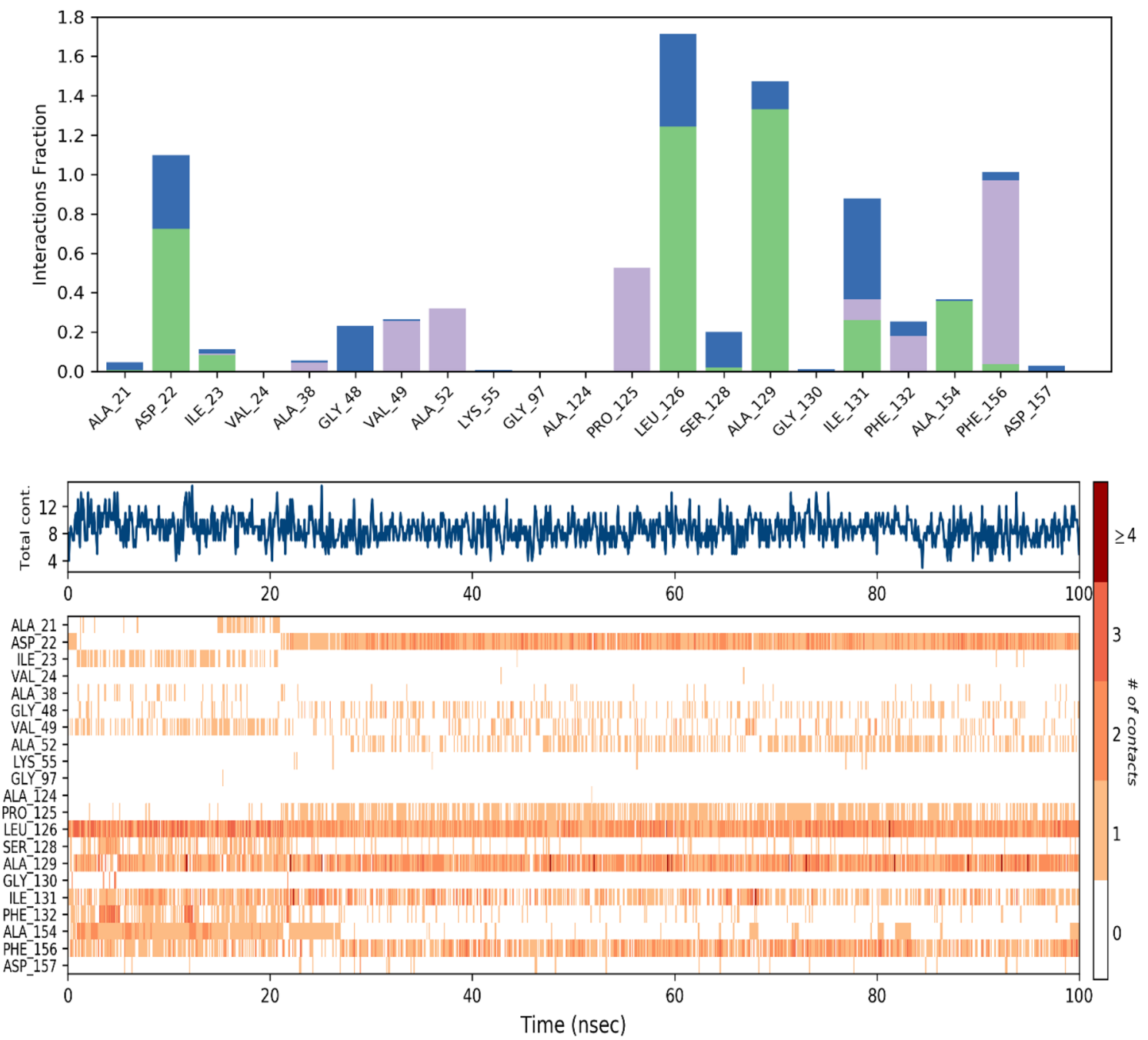

(C) Various interactions between 6W02 and A166.

Fig. 7 (continued)

chance of resistance development in near future. On the other hand, the bioactive phytocompound A166 (Quercitrin) has demonstrated relatively less drug-like properties and has single target capability but can also be used as potential inhibitor against ADRP (6W02) of SARS-CoV-2. Some evidence of clinical trials of different quercitrin derivatives such as quercetin and isoquercitrin are currently emerging for the treatment of COVID-19 in few countries [43]. In Pakistan, clinical trial for adjuvant benefits of Quercetin Phytosome with COVID-19 is reported to undergoing at Liaquat University Hospital Jāmshoro, Sindh in community-based subjects with confirmed SARS-CoV-2 infection. Researchers from Kanuni Sultan Suleyman Training and Research Hospital, Istanbul Turkey are also reported to perform the clinical trial on effect of Quercetin for Prophylaxis and treatment of COVID-19 [43]. Clinical trials are also reported to undergoing in France to evaluate efficacy of the masitinib and isoquercetin combination in moderate and severe COVID-19 patients [43]. However, clinical trial evidence on 6-Hydroxyondansetron (A104) against SARS-CoV-2 replication proteins are yet to be reported. Thus, 6-Hydroxyondansetron with multi-target capabilities as potential inhibitor for Mpro (6LU7) and PLpro (7JRN) replication proteins of SARSCoV-2 can be effectively used as potential drug candidate for treatment of COVID-19 after in vitro and in vivo clinical trials.

\section{Conclusion}

The present studies have characterized 177 phytocompounds from $H$. cordata through GC-MS/LC-MS and they were docked against three receptor proteins, namely Main protease (Mpro), Papain-like protease (PLpro) and ADP ribose 

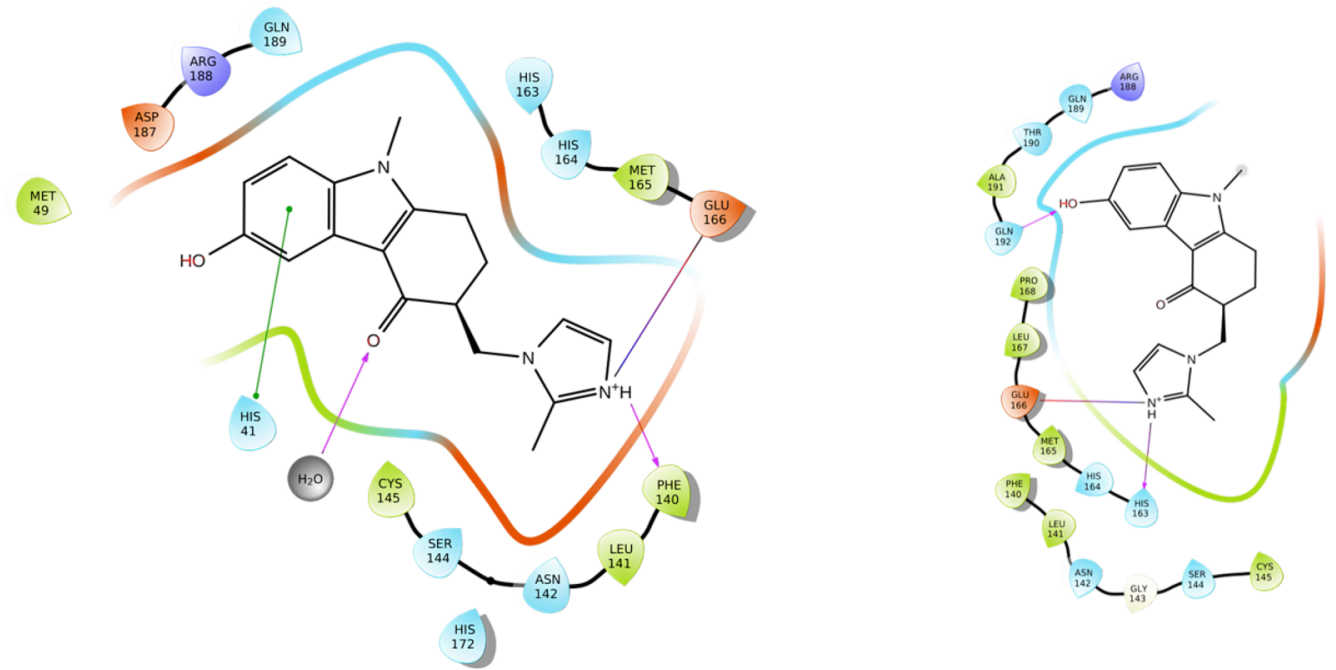

I

II

Charged (negative)

Charged (positive)

Glycine

Hydrophobic

Metal

$\begin{array}{ll}\text { Polar } & \cdots \text { Distance } \\ \text { Unspecified residue } & \rightarrow \text { H-bond } \\ \text { Water } & \rightarrow \text { Halogen bond } \\ \text { Hydration site } & - \text { Metal coordination } \\ \text { Hydration site (displaced) } & \bullet \text { Pi-Pi stacking }\end{array}$

$\rightarrow$ Pi-cation

- Salt bridge

Colvent exposure

(A) Interaction diagram; (I) 6LU and A104 interaction at 0 ns (II) 6LU and A104 interaction at $100 \mathrm{~ns}$

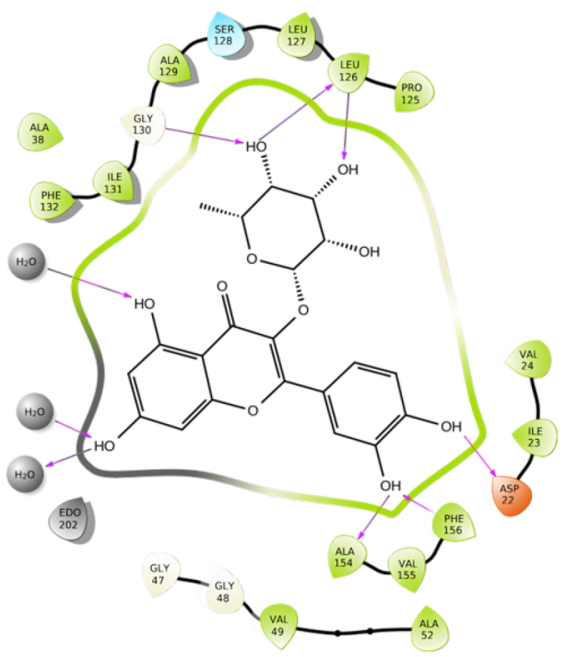

I

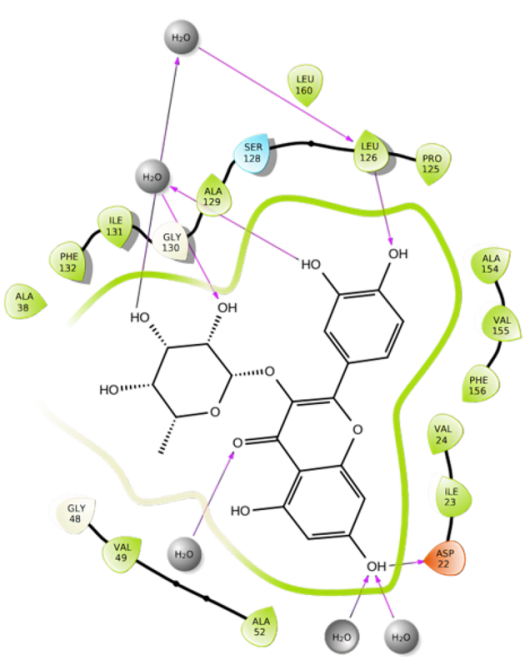

II
Charged (negative)

Charged (positive)

Glycine

Hydrophobic

Metal

Polar
Unspecified residue
Water
Hydration site
$\times \quad$ Hydration site (displaced)

Distance

$\rightarrow \mathrm{H}$-bond

$\rightarrow$ Halogen bond

- Metal coordination

$\times$ Hydration site (displaced) $\bullet$ Pi-Pi stacking

(B) Interaction diagram; (I) 7JRN and A104 interaction at 0 ns (II) 7JRN and A104 interaction at $100 \mathrm{~ns}$

Fig. 8 a Interaction diagram; (I) 6LU and A104 interaction at $0 \mathrm{~ns}$ (II) 6LU and A104 interaction at $100 \mathrm{~ns}$. b Interaction diagram; (I) 7JRN and A104 interaction at $0 \mathrm{~ns}$ (II) 7JRN and A104 interaction at
100 ns. c Interaction diagram; (I) 6W02 and A166 at 0 ns (II) 6W02 and $\mathrm{A} 166$ at $100 \mathrm{~ns}$ 


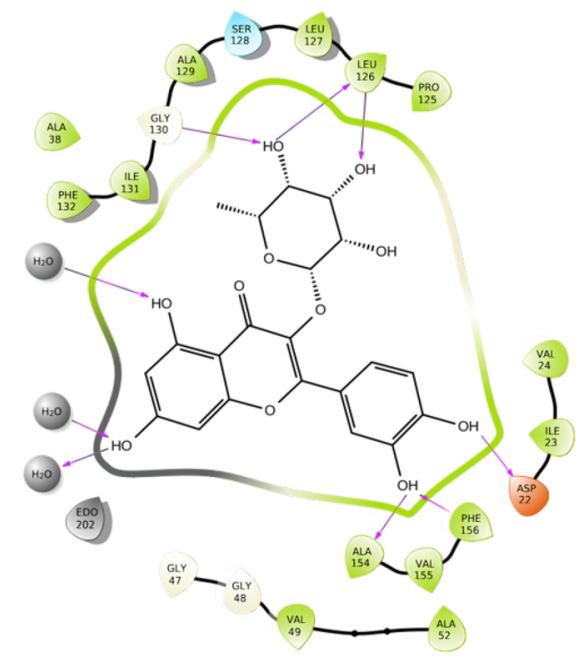

I

Charged (negative)

Charged (positive)

Glycine

Hydrophobic

Metal

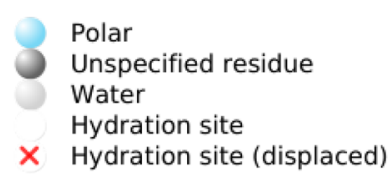

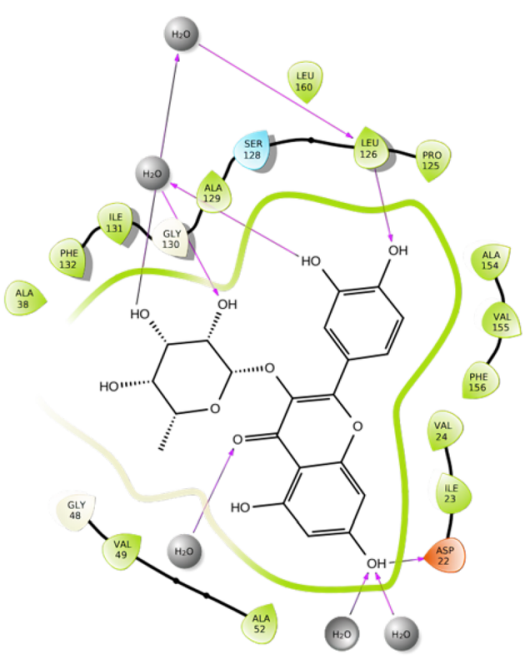

II
Distance

$\rightarrow \mathrm{H}$-bond

$\rightarrow$ Halogen bond

- Metal coordination

\section{(C) Interaction diagram; (I) 6W02 and A166 at 0 ns (II) $6 \mathrm{W02}$ and A166 at $100 \mathrm{~ns}$}

Fig. 8 (continued)

phosphatase (ADRP), of SARS-CoV-2 responsible for controlling the replication process. The result of molecular docking studies clearly revealed that the compound code A104 (6-Hydroxyondansetron) has shown more binding affinity toward two SARS-CoV-2 receptor proteins

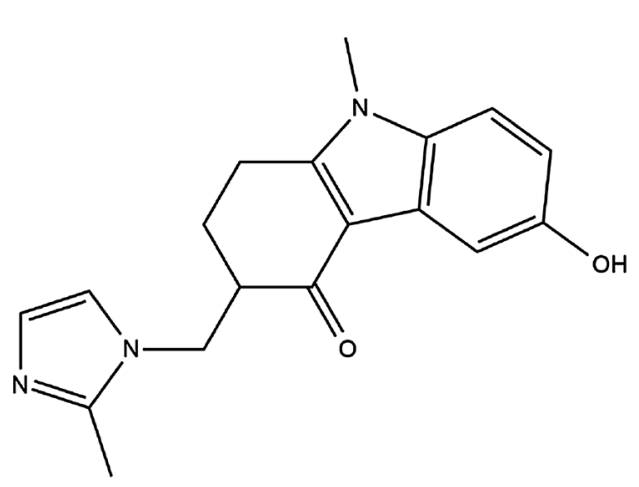

(A)

Fig. 9 Chemical structure and properties of two bioactive phytocompounds with highest binding affinity with SARS-CoV-2 receptors [Mpro (PDB IDs 6LU7), PLpro (7JRN) and ADRP (6W02)]. a 6-Hydroxyondansetron (A104), [Properties: PSA: 60.05; ALogP: 2.3925; Stereo Center Count: 1; Hydrogen Acceptor Count: 3; Hydrogen Donor Count: 1; Composition: C: $69.9 \%, \mathrm{H}: 6.2 \%$, N: $13.6 \%$, O:
Mpro (PDB ID 6LU7) and PLpro (PDB ID 7JRN) with G-score -7.274 and -5.672 , respectively, thus could be used as potential inhibitor for Mpro and PLpro to prevent the replication process of SARS-CoV-2. On the other hand, phytocompounds code A166 (Quercitrin) is also identified<smiles>CC1OC(Oc2c(-c3ccc(O)c(O)c3)oc3cc(O)cc(O)c3c2=O)C(O)C(O)C1O</smiles>

(B)

10.3\%; Formula Weight: 309.36236; Exact Mass: 309.147726878; Molecular Formula: $\mathrm{C}_{18} \mathrm{H}_{19} \mathrm{~N}_{3} \mathrm{O}_{2}$ ]. b Quercitrin (A166), [Properties: PSA: 186.36; ALogP: 0.5892; Stereo Center Count: 5; Hydrogen Acceptor Count: 11; Hydrogen Donor Count: 7; Composition: C: 56.3\%, H: 4.5\%, O: 39.3\%; Formula Weight: 448.3769; Exact Mass: 448.10056146; Molecular Formula: $\mathrm{C}_{21} \mathrm{H}_{20} \mathrm{O}_{11}$ ] 
as another promising inhibitor as it has shown best binding affinity toward protein ADRP (PDB ID 6W02) of SARSCoV-2. Among the two-identified bioactive phytocompounds (ligands), 6-Hydroxyondansetron (A104) has demonstrated more promising properties as drug candidate since it has shown more binding affinity toward multiple receptors. This is very significant as chances of development of drug resistance are much lower in case of multi-target capabilities as inhibitor. The Molecular Dynamic Simulation analysis confirmed that the complex A104-6LU7 and A166-6W02 have shown better stability than the A104-7JRN complex within 100 ns duration. ADME-Tox study further demonstrated that out of two bioactive phytocompounds evaluated, 6-Hydroxyondansetron (A104) passes all the required drug discovery rules, and thus confirmed as viable drug candidate which can be used as potential inhibitor for the two SARSCoV-2 replication proteins (Mpro and PLpro). However, Quercitrin (A166) has demonstrated relatively less druglike properties but can also be used as potential inhibitor for ADRP.

Acknowledgements The authors SKD and PKH are thankful to GBPNIHESD Almora, India for funding support under IERP scheme vide grant No.: GBPI/IERP-NMHS/15-16/51/02 dated 31st March 2016. The authors SKD, PKH and HT are thankful to Director of NIT Arunachal Pradesh, Yupia, Papum Pare, Arunachal Pradesh, and Vice Chancellor of Rajiv Gandhi University, Rono Hills, Doimukh, Arunachal Pradesh, India for laboratory and logistic support.

Author's contribution Authors PKH, HT, BT and SM are senior research guides and mentors who designed the experiment and drafted the manuscript in consultation with all the co-authors. Author SKD, $\mathrm{SM}, \mathrm{PKH}$ and BT significantly contributed to docking and molecular dynamics simulation and identification of the phytocompounds while HT, PKH and SKD significantly contributed to phytochemistry and bioactive phytocompounds analysis.

Funding This study was funded by G.B Pant National Institute of Himalayan Environment and Sustainable Development through IERP scheme, MoEFGoI vide Grant No.: GBPI/IERP-NMHS/15-16/51/02 dated 31st March 2016.

\section{Declarations}

Conflict of interest Authors declare no conflict of interest.

\section{References}

1. World Health Organization (2020) Weekly operational Update on COVID-19 (2020), November. https://www.who.int/

2. Asif M, Saleem M, Saadullah M, Yaseen HS, Al Zarzour R (2020) COVID-19 and therapy with essential oils having antiviral, antiinflammatory, and immunomodulatory properties. Inflammopharmacology. https://doi.org/10.1007/s10787-020-00744-0

3. Song Z, Xu Y, Bao L, Zhang L, Yu P, Qu Y et al (2019) From SARS to MERS, thrusting coronaviruses intothe spotlight. Viruses 11(1):59. https://doi.org/10.3390/v11010059 
4. Yang X, Chen X, Bian G, Tu J, Xing Y, Wang Y et al (2014) Proteolytic processing, deubiquitinase and interferon antagonist activities of Middle East respiratory syndrome coronavirus papain-like protease. J Gen Virol 95(3):614-626

5. Joshi T, Sharma P, Joshi T, Pundir H, Mathpal S, Chandra S (2020) Structure-based screening of novel lichen compounds against SARS Coronavirus main protease (Mpro) as potentials inhibitors of COVID-19. Mol Divers. https://doi.org/10.1007/ s11030-020-10118-x

6. Shin D, Mukherjee R, Grewe D, Bojkova D, Baek K, Bhattacharya A et al (2020) Papain-like protease regulates SARS-CoV-2 viral spread and innate immunity. Nature. https://doi.org/10.1038/ s41586-020-2601-5

7. da Silva JKR, Figueiredo PLB, Byler KG, Setzer WN (2020) Essential oils as antiviral agents, potential of essential oils to treat SARS-CoV-2 infection: an in-silico investigation. Int J Mol Scies 21(10):3426. https://doi.org/10.3390/ijms21103426

8. Santibáñez-Morán MG, López-López E, Prieto-Martínez FD, Sánchez-Cruz N, Medina-Franco JL (2020) Consensus virtual screening of dark chemical matter and food chemicals uncover potential inhibitors of SARS-CoV-2 main protease. RSC Adv 10(42):25089-25099. https://doi.org/10.1039/D0RA04922K

9. Adem S, Eyupoglu V, Sarfraz I, Rasul A, Ali M (2020) Identification of potent COVID-19 main protease (Mpro) inhibitors from natural polyphenols: an in-silico strategy unveils a hope against CORONA. Preprints 2020: 2020030333. https://doi.org/10.20944/ preprints202003.0333.v1

10. Narkhede RR, Pise AV, Cheke RS, Shinde SD (2020) Recognition of natural products as potential inhibitors of COVID-19 main protease (Mpro): In-silico evidences. Nat Prod Bioprosp 10(5):297-306. https://doi.org/10.1007/s13659-020-00253-1

11. Pandit M, Latha N (2020) In silico studies reveal potential antiviral activity of phytochemicals from medicinal plants for the treatment of COVID-19 infection. https://doi.org/10.21203/rs.3. rs-22687/v1

12. Maurya VK, Kumar S, Prasad AK, Bhatt ML, Saxena SK (2020) Structure-based drug designing for potential antiviral activity of selected natural products from Ayurveda against SARS-CoV-2 spike glycoprotein and its cellular receptor. Virus Dis 31(2):179193. https://doi.org/10.1007/s13337-020-00598-8

13. Contreras-Puentes N, Alviz-Amador A (2020) Virtual screening of natural metabolites and antiviral drugs with potential inhibitory activity against 3CL-PRO and PL-PRO. Biomed Pharmacol J 13(2):933-941. https://doi.org/10.13005/bpj/1962

14. Basu A, Sarkar A, Maulik U (2020) Molecular docking study of potential phytochemicals and their effects on the complex of SARS-CoV2 spike protein and human ACE2. Sci Rep 10(1):1-15. https://doi.org/10.1038/s41598-020-74715-4

15. Denaro M, Smeriglio A, Barreca D, De Francesco C, Occhiuto C, Milano G (2020) Antiviral activity of plants and their isolated bioactive compounds: an update. Phytother Res 34(4):742-768. https://doi.org/10.1002/ptr.6575

16. Lau KM, Lee KM, Koon CM, Cheung CSF, Lau CP, Ho HM et al (2008) Immunomodulatory and anti-SARS activities of Houttuynia cordata. J Ethnopharm 118(1):79-85. https://doi.org/10. 1016/j.jep.2008.03.018

17. Jiangang F, Ling D, Zhang L, Hongmei L (2013) Houttuynia cordata Thunb: a review of phytochemistry and pharmacology and quality control. Chin Med. https://doi.org/10.4236/cm.2013.43015

18. Sit NW, Chan YS, Chuah BL, Cheng RJ, Leong WM, Khoo KS (2017) Antiviral, antifungal and antibacterial activities of the Chinese medicinal plants, Houttuynia cordata, Lobelia chinensis and Selaginella uncinata. Southeast Asian J Trop Med Pub Health 48(3):616-627

19. Hirschhorn HH (1983) Botanical remedies of the former Dutch East Indies (Indonesia): part I: Eumycetes, pteridophyta, gymnospermae, angiospermae (monocotyledones only). J Ethnopharm 7(2):123-156. https://doi.org/10.1016/0378-8741(83) 90016-8

20. Chakraborty T, Saha S, Bisht NS (2017) First report on the ethnopharmacological uses of medicinal plants by Monpa tribe from the Zemithang Region of Arunachal Pradesh, Eastern Himalayas. India Plants 6(1):13. https://doi.org/10.3390/plants6010013

21. Danggen O, Mello J, Ering K, Hussain A, Saikia V (2018) Ethnomedicinal plant knowledge among the Adi Tribe of Yingkiong and Mariyang Valley, Upper Siang District, Arunachal Pradesh. India. Int J Pure Appl Biosc 6(1):1504-1511. https://doi.org/10. 18782/2320-7051.5432

22. Kala CP (2005) Ethnomedicinal botany of the Apatani in the Eastern Himalayan region of India. J Ethnobio Ethnomed 1(1):11. https://doi.org/10.1186/1746-4269-1-11

23. Hung PY, Ho BC, Lee SY, Chang SY, Kao CL, Lee SS et al (2015) Houttuynia cordata targets the beginning stage of herpes simplex virus infection. PLoS ONE 10(2):e0115475. https://doi.org/10. 1371/journal.pone.0115475

24. Leardkamolkarn V, Sirigulpanit W, Phurimsak C, Kumkate S, Himakoun L, Sripanidkulchai B (2012) The inhibitory actions of Houttuynia cordata aqueous extract on dengue virus and dengueinfected cells. J Food Biochem 36(1):86-92. https://doi.org/10. 1111/j.1745-4514.2010.00514.X

25. Ling LJ, Lu Y, Zhang YY, Zhu HY, Tu P, Li H et al (2020) Flavonoids from Houttuynia cordata attenuate H1N1-induced acute lung injury in mice via inhibition of influenza virus and Toll-like receptor signalling. Phytomedicine 67:153150. https://doi.org/10. 1016/j.phymed.2019.153150

26. Ren X, Sui X, Yin J (2011) The effect of Houttuynia cordata injection on pseudorabies herpes virus (PrV) infection in vitro. Pharma Biol 49(2):161-166. https://doi.org/10.3109/13880209. 2010.505242

27. Cheng D, Sun L, Zou S, Chen J, Mao H, Zhang Y (2019) Antiviral effects of Houttuyniacordata polysaccharide extract on Murine Norovirus-1 (MNV-1): a human norovirus surrogate. Molecules 24(9):1835. https://doi.org/10.3390/molecules24091835

28. Chiow KH, Phoon MC, Putti T, Tan BK, Chow VT (2016) Evaluation of antiviral activities of Houttuynia cordata Thunb. extract, quercetin, quercetrin and cinanserin on murine coronavirus and dengue virus infection. Asian Pac J Trop Med 9(1):1-7. https:// doi.org/10.1016/j.apjtm.2015.12.002

29. Satthakarn S, Chung WO, Promsong A, Nittayananta W (2015) Houttuynia cordata modulates oral innate immune mediators: potential role of herbal plant on oral health. Oral Dis 21(4):512518. https://doi.org/10.1111/odi.12313

30. Pan A, Naskar B, Prameela GKS, Kumar BP, Mandal AB, Bhattacharya SC (2012) Amphiphile behavior in mixed solvent media I: self-aggregation and ion association of sodium dodecylsulfate in 1, 4-dioxane-water and methanol-water media. Langmuir 28(39):13830-13843. https://doi.org/10.1021/la303281d

31. Jiang H, Solyom AM, Timmermann BN, Gang DR (2005) Characterization of gingerol-related compounds in ginger rhizome (Zingiber officinale Rosc.) by high-performance liquid chromatography/electrospray ionization mass spectrometry. Rapid Comm Mass Spectro 19(20):2957-2964. https://doi.org/10.1002/rcm. 2140

32. Navarro-Reig M, Jaumot J, García-Reiriz A, Tauler R (2015) Evaluation of changes induced in rice metabolome by $\mathrm{Cd}$ and $\mathrm{Cu}$ exposure using LC-MS with XCMS and MCR-ALS data analysis strategies. Anal Bioanal Chem 407(29):8835-8847. https://doi. org/10.1007/s00216-015-9042-2

33. Jin Z, Du X, Xu Y et al (2020) Structure of $M^{\text {pro }}$ from SARSCoV-2 and discovery of its inhibitors. Nature 582:289-293. https://doi.org/10.1038/s41586-020-2223-y

34. RCSB-PDB (RCSB-Protein Data Bank). https://www.rcsb.org 
35. Sastry GM, Adzhigirey M, Day T, Annabhimoju R, Sherman W (2013) Protein and ligand preparation: parameters, protocols, and influence on virtual screening enrichments. J Comput Aided Mol Des 27(3):221-234. https://doi.org/10.1007/s10822-013-9644-8

36. Walters WP (2012) Going further than Lipinski's rule in drug design. Exp Opin Drug Discov 7(2):99-107. https://doi.org/10. 1517/17460441.2012.648612

37. Parida PK, Paul D, Chakravorty D (2020) The natural way forward: Molecular dynamics simulation analysis of phytochemicals from Indian medicinal plants as potential inhibitors of SARSCoV-2 targets. Phytother Res 34(12):3420-3433. https://doi.org/ 10.1002/ptr.6868

38. Tuckerman MBBJM, Berne BJ, Martyna GJ (1992) Reversible multiple time scale molecular dynamics. J Chem Phys 97(3):1990-2001. https://doi.org/10.1063/1.463137

39. Garofalo M, Grazioso G, Cavalli A, Sgrignani J (2020) How computational chemistry and drug delivery techniques can support the development of new anticancer drugs. Molecules 25(7):1756. https://doi.org/10.3390/molecules25071756

40. López-López E, Barrientos-Salcedo C, Prieto-Martínez FD, Medina-Franco JL (2020) In silico tools to study molecular targets of neglected diseases: inhibition of $\mathrm{TcSir}_{2} \mathrm{rp}$, an epigenetic enzyme of Trypanosomacruzi. Adv Protein Chem Struct Bio 122:203-229. https://doi.org/10.1016/bs.apcsb.2020.04.001

41. López-López E, Bajorath J, Medina-Franco JL (2020) Informatics for chemistry, biology and biomedical sciences. J Chem Info and Model. https://doi.org/10.1021/acs.jcim.0c01301

42. Hazarika BB, Gupta D (2020) Modelling and forecasting of COVID-19 spread using wavelet-coupled random vector functional link networks. Appl Soft Comput 96:106626. https://doi. org/10.1016/j.asoc. 2020.106626

43. https://www.clinicaltrials.gov/ct2/results?recrs $=\&$ cond $=\&$ term $=$ quercetin $\&$ cntry $=\&$ state $=\&$ city $=\&$ dist $=$

Publisher's Note Springer Nature remains neutral with regard to jurisdictional claims in published maps and institutional affiliations. 